\title{
$\checkmark$ Research Square \\ Gut microbiota derived metabolites 3-idoleacetic acid with LPS induces generation of IL-35+B cells
}

rongcun Yang ( $\nabla$ ryang@nankai.edu.cn )

Nankai University https://orcid.org/0000-0002-5826-4493

Xiaomin Su

Nankai University

Houbao qi

Nankai University

Minying Zhang

Nankai University

Yunhuan Gao

Nankai University

Yazheng Yang

Nankai University

Huan Yun

Nankai University

Qianjing Zhang

Nankai University

Xiaorong Yang

Nankai University

Yuan Zhang

Nankai University

Jiangshan He

Nankai University

Yaqi Fan

Nankai University

Yuxue wang

Nankai University

Pei Guo

Nankai University

Chunze Zhang

nankai university

\section{Research}


Keywords: Reg4, IAA, Gut microbiota, Lactobacillus, IL-35+B cells, PXR, TLR4

Posted Date: May 5th, 2021

DOI: https://doi.org/10.21203/rs.3.rs-441205/v1

License: (c) (1) This work is licensed under a Creative Commons Attribution 4.0 International License. Read Full License 


\section{Abstract \\ Background}

IL-35 producing B and Treg cells are critical regulators in worldwide chronic illnesses, which are related to disruptions of gut microbiota composition. Whether gut microbiota regulate these $\mathrm{IL}-35^{+}$cells maintains elusive. Here we investigated the regulation of gut microbiota in the IL- $35^{+}$cells through genetically modified mouse models against obesity.

\section{Results}

Here, we first found that gut Reg4 can promote resistance to high-fat diet induced obesity. Using $16 \mathrm{~S}$ rRNA gene-based microbiota analysis combined with LC-MS (Liquid chromatography-mass spectrometry)/MS, we demonstrate that gut Reg4 associated microbiota such as lactobacillus can promote generation of the IL- $35^{+} \mathrm{B}$ cells through producing 3-idoleacetic acid (IAA) in the presence of LPS. HuREG4 ${ }^{I E C t g}$ mice had accumulation of $\mathrm{IL}-35^{+}$cells not only in adipose but also in colon after feeding high-fat diet; whereas decreased IL- $35^{+}$cells in adipose and colon tissues could be detected in Reg 4 knockout (KO) mice. Lower levels of IAA were also detected in the peripheral blood of individuals with obesity. Mechanistically, IAA with LPS mediated IL $35^{+} \mathrm{B}$ cells are through PXR and TLR4. PXR KO or $T L R 4$ KO impaired generation of IL-35+B cells.

\section{Conclusion}

IAA with LPS can induce generation of the IL-35+B cells through PXR and TLR4.

\section{Background}

The gut microbiota influences essential human functions including inflammation, digestion and energy metabolism by modulating immune pathways, neural and endocrine system of the host [1-4].

Disruptions of the microbiota composition and function by factors such as genetics have been suggested to be critical contribution to the growth of the worldwide chronic illness such as metabolic diseases[5-7]. However, that microbiota alterations influence the development and outcome of metabolic diseases is incompletely characterized.

Gut microbiota/metabolites can affect the differentiation and development of immune cells. Multiple transcription factors such as aryl hydrocarbon receptor (AhR) [8, 9], Foxp3 and RORY [10-12] etc. are involved in this process such as AhR contributes to IL22 transcription [8] through an AhR ligand indole-3aldehyde, which is produced by that lactobacillus reuteri. Studies in animal models and in humans have demonstrated that gastrointestinal bacteria/metabolites also participate in B cell differentiation, maturation, and activation $[13,14]$ such as that aryl hydrocarbon contributes to the transcriptional 
program of IL-10 producing regulatory B Cells [15]. IL-35 producing B cells are critical regulators of immunity during multiple diseases such as autoimmune and infectious diseases, and cancer progression [15-19]. Cytokine IL-35, a heterodimer composed of p35 (IL-12A) and Ebi3 (Epstein-Barr virus-induced gene 3), has strong suppressive properties both in vivo and in vitro [20-22]. It can produce widely effects on multiple immune cells such as T cell, B cell, macrophages and dendritic cells etc.[18], and promote generation of the Treg cells and anti-inflammatory M2 macrophages [23, 24], and impede differentiation of the Th1 cells [25]. The expression of IL-35 was dysregulated in inflammatory autoimmune diseases such as systemic lupus erythematosus, rheumatoid arthritis, inflammatory bowel disease, multiple sclerosis, type 1 diabetes, psoriasis, multiple sclerosis, autoimmune hepatitis and experimental autoimmune uveitis etc. [26]. Some $\mathrm{CD}^{+}{ }^{+} \mathrm{Foxp}^{+}$regulatory $\mathrm{T}$ cells[27], $\mathrm{CD} 8^{+}$regulatory $\mathrm{T}$ cells[28], tissue macrophages [24], and dendritic cells (DCs) [29] can also produce IL-35. Whether gut microbiota/metabolites can regulate differentiation and generation of the IL- $35^{+}$cells maintains elusive.

Gut epithelial cells can produce bactericidal substances such as regenerating gene (Reg) family, lysozyme 1, lysozyme 2, secretory phospholipase A2, a-defensins (crytdins) and cryptdin related sequence etc. which play a critical role not only in eliminating pathogen-microbiota but also in maintaining the homeostasis of gut microbiota. Reg4 can be physiologically produced by epithelial cells [30-32]. This protein adopts a typical lectin fold and binds mannose with two calcium-independent sites [33], and induce damage to the bacterial cell wall [33,34]. Here, we found that Reg4 expressed in gut epithelial cells can affect the composition of gut microbiota, especially increased proportion of lactobacillus. Metabolites 3-idoleacetic acid (IAA) produced by increased lactobacillus can promote generation and accumulation of IL-35 $\mathrm{B}$ cells not only in adipose tissues and also in gut tissues and other organs to maintain immune homeostasis.

\section{Results}

\section{Reg4 promotes resistance to high-fat diet induced obesity}

We previously reported that Reg4 could kill E. colithrough complement-dependent pathway [35]. Since increased $E$. coli in colon are related to occurrence and development of multiple diseases such as obesity [36-38], we investigated the role of Reg4 in high-fat diet (HFD) mediated obesity using Reg4 knockout (KO) mice. We found Reg4 KO mice showed more sensitivity to HFD-induced obesity, including more body weight, more weight of fat pad tissues, decreased sensitivity to insulin and reduced tolerance to glucose (Fig.1a-d) although these Reg $4 \mathrm{KO}$ mice had not remarkable changes as compared to control cohoused wild-type (WT) mice under normal chow (Fig. S1a and b). Histochemical staining showed larger adipose cells in Reg4 KO mice than in WT mice (Fig. 1e). Inflammation is related to development of obesity[39]. Inflammatory cytokines such as TNFa, IL-6 and MCP-1 were also increased in the adipose tissues of Reg4 $\mathrm{KO}$ mice (Fig. 1f). To further understand the role of gut Reg4 in HFD-mediated obesity, we generated intestine epithelial cell human REG4 transgenic mice (huREG4IECtg) mice (Fig. S1c-e). These huREG4IECtg mice did not have markedly changes as compared to WT control mice from their littermates under 
feeding a normal chow (Fig. S1f and g). However, while these mice were fed with HFD, huREG4IECtg mice showed markedly resistance to HFD-induced obesity, including less body weight and weight of fat pad tissue, increased sensitivity to insulin and tolerance to glucose (Fig. 1g-j). Histochemical staining showed smaller adipose cells in huREG4 ${ }^{I E C t g}$ mice than those in WT mice (Fig. 1k). Inflammatory cytokines such as TNFa, IL- 6 and MCP-1 were also less in the adipose tissues of huREG4 ${ }^{I E C t g}$ mice than control WT mice (Fig. 1I). Thus, gut derived Reg4 (REG4 in human) is involved in sensitivity to HFD mediated obesity.

\section{Reg 4 is related to accumulation of $\mathrm{IL}-35^{+}$cells}

Since chronic inflammation play a critical role in occurrence and development of obesity [39]. Proinflammatory cells such as M1 macrophages, Th1 cells, CD8 T cells, and mature B cells are often found in adipose tissues of individuals with obesity; Other anti-inflammatory cells including M2 macrophages, regulatory T cells (Tregs), Th2 cells, and eosinophils are also found in the adipose tissues of thin individuals $[39,40]$. Indeed, the number and proportion of M1 and M2 macrophages, Treg and Th1 cells had remarkable changes in the adipose tissues of huREGIIECtg and Reg4KO mice as compared to their control WT mice. Typically, M2 macrophages and Treg cells were markedly increased in the adipose tissues of huREG4IECtg mice, which are resistance to HFD-mediated obesity; whereas in Reg 4 KO mice, which are more sensitive to HFD-mediated obesity, these cells were significantly decreased (Fig. 2a and b). These data support that M2 macrophages and Treg cells are involved in the resistance to HFDmediated obesity $[39,40]$. We next look for the factor(s) which could cause increased M2 macrophages and Treg cells. IL-35 can potentially induce regulatory T cell population and M2 macrophages [41, 42] and reduce gene expression of pro-inflammatory cytokines and Th1 associated transcription factors [41]. Thus we next investigated IL $-35^{+}$cells. The numbers of both IL $-35^{+} \mathrm{B}$ and IL- $35^{+} \mathrm{CD} 4$ cells were markedly reduced in the adipose tissues (fat pad and subcutaneous adipose tissues) of Reg4 KO mice; whereas the $\mathrm{IL}-35^{+}$cells were significantly increased in the adipose tissues in huREG4 ${ }^{I E C t g}$ mice (Fig. 2c and d; Fig. S2a and b). Accumulation of IL-35 $35^{+}$cells in the adipose tissues of huREG ${ }^{I E C t g}$ mice were further confirmed using immunohistochemical staining (Fig. 2e). The transcription levels of Epi3 and P35 also were higher in adipose tissues of huREG ${ }^{I E C t g}$ mice but lower in Reg $4 \mathrm{KO}$ mice (Fig. 2f). Cytokine analyses also showed higher levels of IL-35 in the peripheral blood of huREG4 ${ }^{I E C t g}$ mice; whereas it was lower in the peripheral blood of Reg $4 \mathrm{KO}$ mice (Fig. $2 \mathrm{~g}$ ). We further characterized the IL-35 $\mathrm{B}$ cells. Data showed that increased IL-35 $\mathrm{B}$ cells in the adipose tissue of huREG ${ }^{I E C t g}$ mice with resistance to HFDmediated obesity were belong to immature $C D 19^{+} \lg D^{+} B$ cells (Fig. S2C and d), which are different from IgG producing B cells found in the adipose tissues of mice with sensitivity to obesity $[43,44]$.

We also detected IL- $35^{+} \mathrm{CD} 19^{+} \mathrm{B}$ and IL- $35^{+} \mathrm{CD} 4^{+} \mathrm{T}$ cells in gut tissues and other organ and tissues of these mice fed HFD. There had also markedly accumulation of IL- $35^{+}$cells in the colon LP tissues, Payer's Patch (PP) and spleen in huREG4IECtg mice (Fig. 3a-d; Fig. S3); markedly decreased IL-35+ cells in these tissues could be found in Reg4 KO mice (Fig. 3a-d; Fig. S3). Immunostaining also exhibited increased IL$35^{+}$cells in the colonic tissues of huREG4IECtg mice but less in Reg4 KO mice (Fig. S3b). Higher levels of 
IL-35 were also measured in the colon tissues of huREG ${ }^{I E C t g}$ mice (Fig. 3e). These increased IL-35 ${ }^{+} \mathrm{B}$ cells were also immature $\mathrm{CD} 19^{+} \mathrm{IgG} \mathrm{IDD}^{-} \mathrm{C}^{-} \mathrm{lg} \mathrm{D}^{+} \mathrm{B}$ cells (Fig. S4a). Their phenotypes were $\mathrm{CD} 1 \mathrm{~d}^{+} \mathrm{CD} 5^{+} \mathrm{CD} 25^{+/-} \mathrm{CD} 11 \mathrm{~b}^{+/-} \mathrm{CD} 72^{+} \mathrm{CD} 69^{+/-}$cells (Fig. S4b). Taken together, Reg 4 expressed in gut epithelial cells can promote accumulation of $\mathrm{IL}-35^{+}$cell in the adipose tissue, and also in the gut tissues and peripheral organs.

\section{Reg4 associated gut microbiota/metabolites are related to IL- $35^{+}$cells}

Gut microbiota /metabolites play a critical role in the formation of immune system [1-3]. Reg4 can not only kill E. coli through complement-dependent pathway [35] but also induce damage to bacterial cell wall $[33,34]$, implying that Reg4 might cause changed gut microbiota in gut. Indeed, flow cytometry showed that WGA ${ }^{+}$bacteria increased but LPS ${ }^{+}$bacteria reduced in the fresh stool of huREG $4^{\text {IECtg }}$ mice; whereas $\mathrm{WGA}^{+}$bacteria decreased but LPS ${ }^{+}$bacteria increased in Reg4 KO mice as compared to their control (Fig. 4a), indicating the changed proportion of $\mathrm{Gram}^{+}$and Grambacteria.16S ribosomal RNA (V3-V4 variable region) sequencing analyses of the ileum and colonic contents showed marked changes in the composition of gut microbiota, especially lactobacillus. The proportion of lactobacillus was markedly higher in huREG ${ }^{I E C t g}$ mice (Fig. $4 \mathrm{~b}$ ), consistent with that Reg4 affects the proportion of gut lactobacillus [45]. We also used LC-MS (Liquid chromatography-mass spectrometry)/MS combined with ELISA to analyze metabolites in peripheral blood and stool of huREG4 ${ }^{I E C t g}$ mice. There was markedly increased 3idoleacetic acid (IAA) in the peripheral blood and fresh stool of huREG4IECtg mice; whereas lower levels of IAA could be found in peripheral blood and stool of Reg4 KO mice as compared to their control (Fig. 4c and d).

Since gut microbiota/metabolites play a critical role in forming immune system and in maintaining gut immune homeostasis [1, 2], we hypothesized that accumulation of IL35 $5^{+}$cells in the adipose and gut tissues was derived from changed gut microbiota. To found the relationship between gut microbiota and IL-35 ${ }^{+}$cells, we performed feces exchanged experiments, huREG4 ${ }^{I E C t g}$ mouse feces transferred into WT mice could increase IL-35 cells; whereas Reg $4 \mathrm{KO}$ mouse feces transferred into WT mice reduced the number of IL-35 cells in colonic LP tissues (Fig. S5a and b). Furthermore, CD $19^{+} \mathrm{p} 35^{+}$cells markedly increased in germ-free (GF) mice infused by huREG ${ }^{I E C t g}$ mouse feces but not in GF mice infused by Reg4 KO mouse feces (Fig. S5c and d). All of these suggest that Reg4 associated gut microbiota/metabolites play a role in the generation of IL- $35^{+}$cells.

\section{IAA with LPS promotes binding of PXR with NFkB p65 and RXR}

IAA is a potent bioactive metabolites to activate pregnane $\mathrm{X}$ receptor (PXR) or AhR[8]. There exist multiple potential binding sites of PXR on the promoter region of p35 and Ebi3, two subunits of IL-35 
(https://biogrid-lasagna.engr.uconn.edu/lasagna_search/). However, alone IAA did not cause significantly increased IL- $35^{+}$cells in vitro culture (Fig. 5a), suggesting that other transcription factors may be included. The generation of IL35+B cells needs TLR4 [16], a receptor of LPS. A certain levels of plasma LPS were also often observed in humans and animals with metabolic syndrome [36, 46, 47] (Fig. S6a). Thus, we tried to use IAA plus LPS to induce IL- $35^{+}$cells. Both IAA and LPS could markedly induce more IL-35 ${ }^{+} \mathrm{B}$ cells than LPS or IAA alone in vitro (Fig. $5 a$ and b). Furthermore, there existed markedly a dose response after exposed to different concentration of IAA in the presence of LPS (Fig. 5c). Since IAA can activate PXR or AhR [8], we used PXR or AhR inhibitor to observe their effects on the generation of IL-35 $5^{+}$ cells. PXR inhibitor could produce stronger suppressive role in both IAA and LPS mediated IL- $35^{+} \mathrm{B}$ cells than AhR inhibitor (Fig. 5a and b), suggesting that PXR may play a main role in inducing generation of IL$35^{+}$cells. Meanwhile, NFkB inhibitor also produced marked suppression on the generation of IL- $35^{+}$cells (Fig. $5 a$ and b). Notably, IAA with LPS could effectively induce IL-35 $\mathrm{B}$ cells but not IL-35 ${ }^{+} \mathrm{T}$ cells in vitro (Fig. S6b and c), suggesting that in vivo IL- $35^{+} \mathrm{CD} 4^{+} \mathrm{T}$ cells could be derived from IL-35 produced by IL$35^{+} \mathrm{B}$ cells[26].

p35, a subunit of IL-35 can expanse IL-35-expressing regulatory B cells[19]. CHIP-sequencing and CHIPPCR exhibited that PXR could markedly be enriched in the promoter region of p35 (a subunit of IL-35) in both IAA and LPS but not in IAA or LPS alone treated WEHI B cells (Fig. $5 \mathrm{~d}$ and e), implying that PXR may be a critical factor to regulate the expression of p35. After exposed to IAA plus LPS, PXR markedly increased in the cytoplasma and also in the nucleus (Fig. S7a), suggesting that IAA with LPS promotes the activity of PXR. While cells were exposed to IAA plus LPS, they also promoted both NFkBp65 and RXR to enter nucleus (Fig. S7a). Since that PXR exerts its transcriptional regulatory functions is through dimerization with retinoic $X$ receptor $R X R[48,49]$, we used anti-PXR antibody to perform immunoprecipitation (IP) and check their binding. There indeed existed increased binding of PXR with RXR in nucleus after exposed to IAA plus LPS but not IAA or LPS alone (Fig. 5f; Fig. S7b). These bindings could be impeded by PXR or NFkB inhibitor (Fig. 5f), suggesting that not only PXR but also NFkB is also necessary for the complex. We also used anti-NFkB p65 to perform IP, results also exhibited markedly increased PXR in nucleus after exposed to IAA plus LPS (Fig. 5f). However, IAA with LPS also promoted binding of NFkBp65 to RXR (Fig. 5f), suggesting that NFkBp65 did not only bind with PXR but also with RXR after exposed to both IAA and LPS. Immunostaining also showed the increased binding of PXR, NFkB and RXR after exposed to LPS plus IAA (Fig. 5g). Thus, complexes composed of PXR, NFkB and RXR may be necessary for the expression of IL-35. In addition, inactive PXR is predominantly sequestered in the cytoplasm $[50,51]$ by cytoplasmic androstane receptor (CAR) retention protein and heat shock protein 90 complexes $[52,53]$. IP using anti-PXR also exhibited the binding of PXR with CAR in cytosolic extract (Fig. 5h). Furthermore, this binding decreased in cytoplasma after exposed to IAA or IAA+LPS (Fig. $5 \mathrm{~h}$ ), indicating that active PXR increases. Immunostaining also showed increased PXR in the cytoplasma and nucleus after IAA plus LPS (Fig. 5i). All of these suggest that IAA can induce PXR to enter nucleus to promote IL-35 expression through binding with NFkB p65 and RXR. 


\section{IAA with LPS mediated IL-35 $B$ cells need PXR and TLR4}

To further demonstrate that IAA and LPS mediated IL-35 cells is dependent on PXR and NFkB p65, we employed PXR KO and TLR4 KO mice (TLR4 can activate NFkB p65). Since active PXR is regulated by the CAR retention protein $[52,53]$, the effects of $C A R \mathrm{KO}$ on IL-35+ cells are also observed. Meanwhile, we also observed $A h R \mathrm{KO}$ mice, in which AhR is potentially recognized by IAA [8]. The spleen cells from WT, $P X R$ $\mathrm{KO}, T L R 4 \mathrm{KO}, C A R \mathrm{KO}$ and $A h R \mathrm{KO}$ mice were cultured in the medium with IAA plus LPS. IAA plus LPS did not effectively induce IL- $35^{+} \mathrm{B}$ cells from spleen cells of $P X R \mathrm{KO}$ or TLR4 KO mice; whereas splenic cells from WT mice could produce more IL-35+B cells in the presence of IAA with LPS (Fig. 6a; Fig. S8a). Notably, CAR KO had also significant effects on the generation of IL-35 ${ }^{+} \mathrm{B}$ cells as compared to WT mice (Fig. 6a; Fig.S8a), consistent with above findings (Fig. 5). After in vivo injecting IAA plus LPS into PXR KO, $C A R \mathrm{KO}, T L R 4 \mathrm{KO}$ and also AhR KO mice, IAA plus LPS could promote generation and accumulation of IL35 ${ }^{+}$cells in WT mice but not in PXR KO and TLR4 KO mice (Fig. 6b and c; Fig. S8b and d). Higher levels of IL-35 could be detected in the spleen, Payer patch (PP) and peripheral blood of WT but not in PXR KO and TLR4 KO mice (Fig. 6d). Again there were less IL-35 in the spleen, PP and peripheral blood of CAR KO mice (Fig. 6d). Immunostaining also further confirmed the increased IL- $35^{+} \mathrm{CD} 19$ cells in the spleen of WT mice injected by IAA with LPS (Fig. S8c). In addition, AhR KO also affected generation of IL- $35^{+}$cells in vitro and in vivo in some degree (Fig. 6a-d), suggesting that AhR is partly involved in IAA plus LPS mediated IL- $35^{+}$cells.

Since the proportion of lactobacilli was significantly higher in the ileum and colon of huREG4IECtg mice, we isolated one strain of dominant lactobacillus from fresh stool of huREG4IECtg mice, Lactobacillus reuteri, which can produce IAA (Fig. S9a and b). We also generated mutated lactobacillus (lactobacillus ${ }^{\text {DiaaM }}$ ), which could not produce IAA. While these lactobacilli or lactobacilliDiaaM were infused into mice, lactobacilli could induce the production of IL-35 in the presence of LPS; whereas lactobacilliDiaaM. did not (Fig. 6e; Fig. S9c and d). Notably, lactobacilli did not induce the generation of IL$35^{+} \mathrm{B}$ cells in PXR KO or TLR4 KO mice (Fig. 6e; Fig. S9c and d). There were higher levels of IL-35 cytokine in the spleen, PP and peripheral blood of WT but not PXR KO or TLR4 KO mice infused lactobacillus (Fig. 6f). Unlike to lactobacillus, infusion of lactobacillus ${ }^{\text {DiaaM }}$ did not affect the levels of IAA in spleen, PP and peripheral blood of mice (Fig. $6 \mathrm{~g}$ ). Thus, IAA generated by Reg4 associated lactobacillus could promote the generation of IL-35+cells in WT mice but not in PXRKO or TLR4 KO mice. Taken together, IAA can induce the generation of IL-35 $\mathrm{B}$ cells through PXR and TLR4.

\section{Lower levels of IAA are detected in the peripheral blood of individuals with obesity}

Individuals with obesity are also associated with gut microbiota and metabolites [54, 55]. The systematic review indicates that probiotics, which could produce IAA, may have beneficial effects on weight loss in overweight adults [56]. Thus, we investigated the relevance of gut microbiota-derived IAA with body 
weight in 208 individuals with different body mass index (BMI). The concentrations of microbiota metabolites IAA were lower in individuals with increased BMI (Fig 7a). Indeed, individuals with obesity have lower IAA (Fig 7b). Since increased IAA could potentially induce generation of IL- $35^{+}$cells in human, we also detected the levels of IL-35 in peripheral blood of individuals with overweight or obesity. Unexpectedly, IL-35 was very low in all individuals with different BMI. Thus, there exist lower levels of IAA in the individuals with overweight or obesity.

\section{Discussion}

Here we found that Reg4 derived from gut epithelial cells is related to HFD-mediated obesity. There exist a markedly accumulation of IL- $35^{+}$cells in the adipose tissues and gut tissues and other organs such as spleen in huREG4IECtg mice, which are resistant to HFD-mediated obesity; whereas the number of IL-35 cells in Reg4 KO mice is less than their control WT mice. Altered gut microbiota in huREG4 ${ }^{I E C t g}$ or Reg4 $\mathrm{KO}$ mice have direct relationship with IL-35+cells. We also found the accumulation of $\mathrm{IL} 35^{+}$cells is related to lactobacillus derived metabolites IAA. IAA can induce generation and accumulation of $\mathrm{IL} 35^{+} \mathrm{B}$ cells in the presence of LPS through activating PXR. In addition, lower levels of IAA are also found in the individuals with obesity. These data suggest that there may exist an axis of Reg4 /gut microbiota / IAA/IL- $35^{+}$B cells/resistance to HFD-mediated obesity.

Gastrointestinal bacteria/metabolites participate in B cell differentiation, maturation and activation [13, 14]. Mice depleted of endogenous bacteria following administration of broad-spectrum antibiotics do not develop II-10 producing Bregs[57]. We here demonstrate that IAA produced by Reg4 associated lactobacillus could induce generation of IL-35+B cells, suggesting that gut microbiota are not only involved in the differentiation of IL-10 producing Bregs but also IL-35 producing B cells. IL-35 expression can be regulated by multiple factors. B cells isolated from WT mice can increase the expression of p35 and Ebi3 upon activation via TLR4 and CD40[16]. The percentage of $\mathrm{p}^{2} 5^{+} \mathrm{Ebi}^{+} \mathrm{B}$ cells and levels of IL-35 are dramatically up-regulated when treated with B cell activating factor (BAFF)[58]. Production of IL-35 by Bregs may also be mediated through binding of basic leucine zipper transcription factor ATF-like (BATF)interferon regulatory factors(IRF)4-IRF8 complex to i/12a and ebi3 promoter elements [59]. Under inflammatory conditions, Ebi3 is also upregulated by the epigenetic mechanism histone acetylation [60]. In addition, IL-35 signaling is transduced through the signal transducer and activator of transcription (STAT)1-STAT4 heterodimer to activate the expression of IL-35 subunits IL $12 A$ and EBi3 in the form of a positive feedback loop [61].

We demonstrate that IAA with LPS induced IL- $35^{+}$cells are through activating PXR, NFkB, RXR and also CAR. The tryptophan metabolites IAA has been reported to act as agonists of PXR[62]. Others also found that indole and indolic acid derivatives are potent bioactive metabolites that affect intestinal barrier integrity and immune cells in mice by activating $\operatorname{PXR}[8,63,64]$. Our results exhibited that IAA with LPS can not only promote the activity of transcription factor PXR but also RXR and CAR, which are necessary to induce the expression of p35, a subunit of IL-35. Relationship and interaction among PXR, CAR and 
RXR have been found in multiple organ and tissues [65-67]. Several reports also show the relationship between IL-35 and NF-kB such as that B cells isolated from WT mice increase the expression of p35 and Ebi3 upon activation via TLR4 ${ }^{+}$and $C D 40[16]$. Other also found influenza A virus (IAV)-induced IL-35 transcription is regulated by NFKB[68]. Additionally, a direct chemical communication between the intestinal symbionts and PXR can also regulate mucosal integrity through a pathway that involves luminal sensing and signaling by TLR4 [63].

So far, a plethora of microbial intestinal catabolites of tryptophan (MICT), including indole (IND), indole-3acetate (IAA), tryptamine (TA), indole-3-pyruvate (IPY), indole-3-lactate (ILA), indole-3-acrylate (IAC), indole3-propionate (IPA), skatole (3MI), indole-3-acetamide (IAD), indole-3-ethanol (IET), indole-3-aldehyde (IAID), and indole-3-acetaldehyde have been identified[62]. These metabolites exert an important role in inducing the differentiation of immune cells such as that IAID produced by lactobacillus to contributes to AhR-dependent IL-22 transcription $[8,64,69]$ and activate innate lymphoid cells (ILCs) [8]. AhR also contributes to the transcriptional program of IL-10-producing regulatory B cells[15]. We found that IAA can induce the IL-35+B cells through activating PXR receptors.

Our results suggest that lactobacillus producing IAA may have a negative relationship with development of obesity. The peripheral blood of individuals with metabolic syndrome exhibits lower levels of IAA in human and mice. Others also found that the abundance of IAA and body mass index (BMI) show strong negative correlation [7].

\section{Conclusion}

We here found that gut Reg4 can promote resistance to high-fat diet induced obesity and accumulation of IL-35 $5^{+}$cells in adipose tissues. We demonstrate that gut Reg4 associated microbiota such as lactobacillus can promote generation of IL-35+ $B$ cells through producing 3-idoleacetic acid (IAA) in the presence of LPS. Lower levels of IAA could be detected in the peripheral blood of individuals with obesity. Finally, we demonstrate that IAA with LPS mediated IL $35^{+} \mathrm{B}$ cells are through PXR and TLR4. PXR KO or $T L R 4 \mathrm{KO}$ impaired generation of IL-35 $\mathrm{B}$ cells. Thus, IAA with LPS can induce generation of the IL- $35^{+} \mathrm{B}$ cells through PXR and TLR4.

\section{Methods}

All regents and oligoes used in this study were listed in supplementary Table S1.

\section{Mice}

Four-to six-week-old male or female C57BL/ 6 mice were obtained from Nanjing Animal Center, Nanjing, China; AhR KO mice were from the Third Military Medical University, Chongqing, China; PXR KO mice and CAR KO mice from Chinese Academy of Inspection and Quarantine, Tianjin, China; TLR4 KO mice were from Shanghai Model Organisms Center, Shanghai, China. All experimental litters were bred and 
maintained under specific pathogen-free conditions in Nankai University. Experiments were carried out using age- and gender- matched mice. All the procedures were conducted according to the Institutional Animal Care and Use Committee of the Model Animal Research Center. Animal experiments were approved by the Institute's Animal Ethics Committee of Nankai University. All experimental variables such as husbandry, parental genotypes and environmental influences were carefully controlled.

C57BL/ 6 germ-free (GF) mice were generated by Beijing Animal Center. All experiments in GF mice were performed in Institute of Laboratory Animal Science区Chinese Academy of Medical Sciences (CAMS) Comparative Medical Center, Peking Union Medical College (PUMC), Beijing 100021, China.

Reg4 deficient (KO) mice were generated by CRISPR/Cas-mediated genome engineering as described before(Qi et al, 2020).

Human REG4 transgenic mice ( huREG4IEC tg) mice were prepared by Nanjing Animal Center. HD5 promoter, which may specifically promote the REG4 expression in gut Paneth cells, was conjugated into Pinsulator-pHD5-promoter-CDS-poly plasmid. The fragment of REG4-CDS and polyA were cloned into HD 5 promoter-Pinsulator. This conjugation was demonstrated using primers (REG4-HD5-tF:

CATCCAACTCCAGGACGGAGTC and REG4-HD5-tR: CACCTGTAACATTGGCACTTTG) and sequencing using the primers (Promoter-cx tF: GTTTGCTGGGTCAGAACTGA and Promoter-cx tR:

GTAATTTAGGTGCGTACAGCC). HuREG4IEC tg mice were identified using the following primers (HD5Test-Tf:CTGTCTCAGGTCTTCTCCCAG and REG4 -PA-F: GATCTTTTTCCCTCTGCCAAA, which produced $323 \mathrm{bp}$ band in tg mice and no band in WT mice). Human REG4 tg mice or WT siblings were from a cross between WT mice and human REG4 tg mice (heterozygous mice).

\section{Human samples}

For human serum collection, 208 adult participants, among which 42 with BMl $<18.5 \mathrm{~kg} / \mathrm{cm} 2,41$ with BMI $18.5-24 \mathrm{~kg} / \mathrm{cm} 2,43$ with BMI $24-27 \mathrm{~kg} / \mathrm{cm} 2,42$ with BMI $27-30 \mathrm{~kg} / \mathrm{cm} 2$ and 40 with BMI $\geq 30 \mathrm{~kg} / \mathrm{cm} 2$ were selectively recruited. More than half $(54.3 \%)$ were males and the mean age was 42 years $(\mathrm{SD}=13$ years). The mean BMI was $25.05 \pm 5.07 \mathrm{~kg} / \mathrm{cm} 2$. All participants were free of acute stress conditions such as fever and diarrhea. Height and weight were measured to the nearest $0.1 \mathrm{~cm}$ and $0.1 \mathrm{~kg}$ without shoes or heavy clothing using a calibrated stadiometer (GL-310, Seoul, Korea). Participants were instructed to fast for $\geq 12$ hours before blood sampling the next morning. This study was conducted with approval from the Institutional Review Board at Nankai University, Tianjin Union Medical Center and Tianjin First Central Hospital. Participants were recruited from the health screening centers of Tianjin Union Medical Center and Tianjin First Central Hospital. All participants provided written informed consent.

\section{Mouse models}

For high-fat diet model, 6-8 week old male mice and their control littermates were fed using high-fat diet (D12492, protein $26.2 \%$, carbohydrate, $26.3 \%$ and Fat $34.9 \%$ ) and control diets (D12450B $60 \%$ of calories may be derived from fat), which was from Research Diets, Inc..(NJ, USA). 
For microbiota transplantation, 6- to 8-week-old mice were treated with pan-antibiotics (ampicillin (A, 1 $\mathrm{g} / \mathrm{L}$, Sigma), vancomycine $(\mathrm{V}, 0.5 \mathrm{~g} / \mathrm{L})$, neomycin sulfate $(\mathrm{N}, 1 \mathrm{~g} / \mathrm{L})$, and metronidazole $(\mathrm{M}, 1 \mathrm{~g} / \mathrm{L})$ ) via the drinking water. Water containing antibiotics was exchanged every three days. To confirm the elimination of bacteria, stool was collected from antibiotic-treated and untreated mice and cultured in anaerobic and aerobic condition. The bacteria were counted under microscope. Then cecal contents from detergent treated mice or bacteria ( $1 \times 109)$ were suspended in $1 \mathrm{ml}$ PBS with $30 \%$ glycerol. Mice (4 weeks old) were removed from the isolator and were orally administered $200 \mathrm{ml}$ of fecal suspension or bacteria made using glycerol stocks.

For lactobacillus transplantation, mice were treated with pan-antibiotics via the drinking water for two weeks. After confirming the elimination of bacteria, $1 \times 109 \mathrm{CFU} / 0.2 \mathrm{ml}$ PBS Lactobacillus was infused into mice with intraperitoneal injection with $2 \mathrm{mg} / \mathrm{kg}$ LPS (once/ week for three weeks). After infusing lactobacillus, mice were fed with enriched $(0.48 \%)$ tryptophan diets.

For in vivo administration of IAA plus LPS, mice were randomly divided into 4 groups, normal group with $0.2 \mathrm{ml}$ PBS only, IAA group i.p with $500 \mathrm{mg} / \mathrm{kg}$ IAA diluted in DMSO, LPS group with $2 \mathrm{mg} / \mathrm{kg}$ 0111:B4 in $0.2 \mathrm{ml}$ PBS, and IAA plus LPS group with $500 \mathrm{mg} / \mathrm{kg}$ IAA and $2 \mathrm{mg} / \mathrm{kg}$ 0111:B4. After administration for $24 \mathrm{hrs}$, spleen and PP tissues were separated for further analyses.

\section{Ex vivo stimulation}

For Ex vivo stimulation, mice spleen cells were collected. $5 \times 106$ cells per well were seeded into 24 -wells plate, and stimulated with IAA $(100 \mu \mathrm{M})$, LPS $(100 \mathrm{ng} / \mathrm{ml})$, or IAA $(100 \mu \mathrm{M})$ plus LPS $(100 \mathrm{ng} / \mathrm{ml})$ with or without PXR inhibitor(10uM), AHR inhibitor (10uM), or NF-KB inhibitor (10uM) for 24hrs.

For WEHI231 B cells stimulation, WEHI231 B cells were seeded in 24-wells plate. The cells were then stimulated with IAA and LPS with or without PXR inhibitor or NF-KB inhibitor for 3hrs or 6 hrs, and harvested for WB, CHIP-SEQ and CHIP-PCR analyses.

\section{Metabolism experiments}

For glucose and insulin tolerance, after 5 hrs fasting, baseline blood glucose levels were measured using a Nova Max Plus GlucoseMeter. Mice were then injected intraperitoneally with $2 \mathrm{~g}$ glucose per kg body weight in sterile PBS or with $0.5 \mathrm{U}$ insulin per kg body weight (Sigma, St. Louis, Missouri), and blood glucose levels were measured at different times after injection.

\section{Gut microbiota analyses}

Previous protocol was used in gut microbiota analyses (Qi et al, 2019). Brefiely, Gut microbiota was analyzed by Majorbio Biotechnology Company (Shanghai, China) using primers that target to the V3-V4 regions of 16S rRNA. Once PCR for each sample was completed, the amplicons were purified using the QIAquick PCR purification kit (Qiagen Valencia, CA), quantified, normalized, and then pooled in preparation for emulsion PCR followed by sequencing using Titanium chemistry (Roche, Basel 
Switzerland) according to the manufacturer's protocol. Operational Taxonomic Unit (OTU) analysis was performed as follows: sequences were processed (trimmed) using the Mothur software and subsequently clustered at $97 \%$ sequence identity using cd-hit to generate OTUs. The OTU memberships of the sequences were used to construct a sample-OTU count matrix. The samples were clustered at genus and OTU levels using the sample-genus and sample-OTU count matrices respectively. For each clustering, Morisita-Horn dissimilarity was used to compute a sample distance matrix from the initial count matrix, and the distance matrix was subsequently used to generate a hierarchical clustering using Ward's minimum variance method. The Wilcoxon Rank Sum test was used to identify OTUs that had differential abundance in the different sample groups.

For lactobacillus isolation, $100 \mathrm{mg}$ fresh stool samples were collected and diluted in $2 \mathrm{ml}$ BPS solution, and cultured on Rogosa SL selective medium (Sigma-Aldrich) for Lactobacillus enumeration, and then colonies were identified and purified using $16 \mathrm{~s}$ ribosomal DNA sequence analyses for the speciation of colonial genotype. The lactobacilli were cultured in deMan, Rogosa, Sharpe (MRS; 3 M Health Care, St. Paul, MN) media and also grown on MRS agar containing either $10 \%$ sucrose. Anaerobic conditions were generated with sachets of AnaeroPack-Anaero (Mitsubishi Gas Chemical, Japan) in an air-tight jar. At 24 $\mathrm{h}$ of cultivation in liquid media, isolated lactobacillus Ruteri could reach $1 \times 109 \mathrm{CFU} / \mathrm{ml}$ ).

\section{laaM gene deletion in lactobacillus}

For lactobacillus iaaM gene deletion, the upstream and downstream fragments of the iaaM gene of lactobacillus were first amplified. The purified upstream and downstream homologous fragments were inserted into the Xoh I, Pem I and Sac I, Bgl II digestion sites of the pNZ5319 plasmid, respectively. Receptive cells of lactobacillus were prepared and the recombinant pNZ5319 plasmid was electrotransferred into the receptive cells of lactobacillus with the electrotransfer parameters of $1.7 \mathrm{kV}$ (2 mm electrode cup), $200 \Omega$ resistance and $25 \mu \mathrm{F}$ capacitance. Single colone of chloramphenicol-resistant lactobacillus were selected, and the iaaM-up-F/R, iaaM-down-F/R, CM-F/R primers were used to validate the strains with single exchange. The single-exchange strains were cultured for 3 generations per day at $30^{\circ} \mathrm{C}$, and the suspensions were taken at 40 generations for double-exchange strain screening. The colonies that could grow normally on plates containing chloramphenicol resistance but not on solid plates containing erythromycin resistance were selected. The screened double exchangers were verified using iaaM-F/R PCR. Double-exchanger positive bacteria were prepared as receptor cells and electrotransfected with pNZTs-Cre plasmid for 3 generations per day to about 10 generations, eliminating the chloramphenicol resistance gene from the genome and verified using CM-F/R PCR. The heat-sensitive plasmid pNZTs-Cre was eliminated by incubation in an incubator at $42^{\circ} \mathrm{C}$ for $3-5 \mathrm{~h}$.

\section{LC-MS (Liquid chromatography-mass spectrometry)/MS}

The samples were thawed at room temperature. All samples were extracted with $300 \mathrm{~L}$ of methanol, and $10 \mathbb{} \mathrm{L}$ of internal stardard $(2.9 \mathrm{mg} / \mathrm{mL}, \mathrm{DL}-\mathrm{O}-$-Chlorophenylalanine) was added. The samples were vortexed for $30 \mathrm{~s}$, and centrifuged at $12000 \mathrm{rpm}$ and $4 \mathrm{oC}$ for $15 \mathrm{~min}$. Waters ACQUITY UPLC HSS T3 column (2.1 $\mathrm{mm} \otimes 100 \mathrm{~mm}, 1.8 \square \mathrm{M})$ was used. Chromatographic separation conditions are : column temperature, $40 \mathrm{oC}$; 
Mobile phase A, water $+0.1 \%$ formic acid; Mobile phage $B$, acetonitrile $+0.1 \%$ formic acid; Flow rate, 0.35 $\mathrm{mL} / \mathrm{min}$; injection volume, $6 \mathrm{LL}$. MS parameters used for ESI+ were: capillary voltage, $1.4 \mathrm{kV}$; Sampling cone, $40 \mathrm{~V}$; Source temperature, $120^{\circ} \mathrm{C}$; Desolvation temperature, $350^{\circ} \mathrm{C}$; Cone gas flow, $50 \mathrm{~L} / \mathrm{h}$; Desolvation gas flow, $600 \mathrm{~L} / \mathrm{h}$; Collision energy, 10-40V; Ion energy, 1V; Scan time, $0.03 \mathrm{~s}$; Inter scan time, $0.02 \mathrm{~s}$; scan range, 50-1500 m/z. MS parameters used for ESI- were: capillary voltage, $1.3 \mathrm{kV}$; Sampling cone, $23 \mathrm{~V}$; Source temperature, $120^{\circ} \mathrm{C}$; Desolvation temperature, $350^{\circ} \mathrm{C}$; Cone gas flow, $50 \mathrm{~L} / \mathrm{h}$; Desolvation gas flow, $600 \mathrm{~L} / \mathrm{h}$; Collision energy, 10-40V; Ion energy, 1V; Scan time, $0.03 \mathrm{~s}$; Inter scan time, $0.02 \mathrm{~s}$; and scan range, $50-1500 \mathrm{~m} / \mathrm{z}$. Analysis platform was performed by ACQUITYTM UPLC-QTOF.

The data was performed by feature extraction and preprocessed with Masslynx 4.1 software (Waters), and then normalized and edited into two-dimensional data matrix by excel 2010 software, including retention time(RT), mass, observations(samples) and peak intensity. The data after editing were performed Multivariate Analysis (MVA) using SIMCA-P 13.0 software (Umetrics AB, Umea, Sweden).

\section{Cell isolation and flow cytometry}

Previous reported protocol was used in cell isolation and flow cytometry(Cao et al, 2016). Briefly, singlecell suspensions of Peyer's patches (PP) and spleen of mice were prepared by mashing in a cell strainer $(70 \mathrm{~mm})$, stained and analyzed by flow cytometry. For the staining of lamina propria (LP) lymphocytes, gut were isolated, cleaned by shaking in ice-cold PBS four times before tissue was cut into $1 \mathrm{~cm}$ pieces. The epithelial cells were removed by incubating the tissue in HBSS with $2 \mathrm{mM}$ EDTA for 30 min at 37oC with shaking. The LP cells were isolated by incubating the tissues in digestion buffer (DMEM, $5 \%$ fetal bovine serum, $1 \mathrm{mg} / \mathrm{ml}$ Collagenase IV (Sigma-Aldrich) and DNase I (Sigma-Aldrich) for $40 \mathrm{~min}$. The digested tissues were then filtered through a 40-mm filter. Cells were resuspended in $10 \mathrm{ml}$ of the $40 \%$ fraction of a 40: 80 Percoll gradient and overlaid on $5 \mathrm{ml}$ of the $80 \%$ fraction in a $15 \mathrm{ml}$ Falcon tube. Percoll gradient separation was performed by centrifugation for $20 \mathrm{~min}$ at 1,800 rpm at room temperature. LP cells were collected at the interphase of the Percoll gradient, washed and resuspended in medium, and then stained and analyzed by flow cytometry. Dead cells were eliminated through 7-AAD staining. For the staining of immune cells in adipose tissues, adipose tissues first were cut into smaller pieces and then digested in digestion buffer (201 / ml Collagenase I (Sigma-Aldrich) )for $35 \mathrm{~min}$.. The digested tissues were then filtered through a $40-\mathrm{mm}$ filter.

For analysis of different immune cell populations, the cells were washed with staining buffer containing $2 \%$ FBS, 1 mM EDTA and 0.09\% NaN3 and surface staining was performed with APC, FITC, PercP, BV 605 or PE-labeled anti-CD4, CD19, p35, EPI3, CD11c, MHCII, F4/80, CD11b, Ly6C and CD45 antibodies and analyzed using FACScan flow cytometry (Su et al, 2014).

For intracellular staining, the cells were cultured and stimulated with $50 \mathrm{ng} / \mathrm{ml}$ phorbol 12-myristate 13acetate (PMA, Sigma) and $1 \mu \mathrm{g} / \mathrm{ml}$ ionomycin (Sigma) in the presence of GolgiStop ( $10 \mathrm{ng} / \mathrm{ml}, \mathrm{BD}$ Biosciences). After incubation for 6 hrs, cells were washed in PBS, and then fixed in Cytofix/Cytoperm, permeabilized with Perm/Wash buffer (BD Biosciences), and stained with FITC-, PE-, APC- APC/cy7-, 
PerCP/Cy5.5- or PE/cy7-conjugated antibodies. Meanwhile, dead cells were eliminated through 7-AAD staining.

For absolute cell number count, spleen tissue and whole PP nodes of mice were weighed and single-cell suspensions were prepared for flow staining analysis. The total number of cells per gram of spleen or PP node was counted and then multiplied by the proportion of positive cells to obtain the absolute number of cells.

\section{H \& E staining}

For hematoxylin/eosin (H\&E) staining, previously reported methods were used in this experiment (Su et al, 2014). Briefly, adipose tissues were fixed in $4 \%(w / v)$ paraformaldehyde buffered saline and embedded in paraffin, $5 \mu \mathrm{m}$ sections colon sections were cut and stained with H\&E.

\section{Immunostaining}

For immune staining, previous reported protocol was used(Shang et al, 2019). Briefly, colon tissues or spleen were embedded in OCT compound (Tissue-Tek, Torrance, CA) and frozen over liquid nitrogen. 5$\mu \mathrm{m}$-thick sections were prepared from frozen tissue and fixed in acetone $\left(-20^{\circ} \mathrm{C}\right)$ for $10 \mathrm{~min}$. After rehydration in PBS for 5 min and further washing in PBS, tissue sections were blocked with $1 \%(\mathrm{w} / \mathrm{v})$ BSA and $0.2 \%(\mathrm{w} / \mathrm{v})$ milk powder in PBS (PBS-BB). The primary antibody was added in PBS-BB and incubated overnight at $4^{\circ} \mathrm{C}$. After washing (three times, 5 min each), tissue was detected with DAB kit or fluorescence labeled second antibody. Nuclei were stained by DAPI.

\section{Immunoprecipitation and immunoblot}

Immunoprecipitation and immunoblot were performed according to previous methods (Su et al, 2014). The cells were lysed with cell lysis buffer (Cell Signaling Technology), which was supplemented with a protease inhibitor 'cocktail' (Calbiochem). The protein concentrations of the extracts were measured using a bicinchoninic acid assay (Pierce). For the immunoblot, hybridizations with primary antibodies were conducted for $1 \mathrm{~h}$ at room temperature in blocking buffer. The protein-antibody complexes were detected using peroxidase-conjugated secondary antibodies (Boehringer Mannheim) and enhanced chemiluminescence (Amersham).

\section{CHIP-seq and CHIP-PCR}

Chromatin immunoprecipitation (ChIP)-PCR was performed using EZ-ChIP ${ }^{\text {TM }}$ Chromatin Immunoprecipitation Kit (Millipore) according to our previously reported methods(Gao et al, 2018). Briefly, the cells were crosslinked with $1 \%$ paraformaldehyde and incubated with rotation at room temperature. Crosslinking was stopped after 10 min with glycine to a final concentration of $0.125 \mathrm{M}$ and incubated 5 min further with rotation. Cells were washed with ice cold PBS (containing 1\% PMSF) 3 times and immediately resuspended in SDS lysis buffer (containing 1\% PMSF). Cell lysates were sonicated for 40 cycles of $30 \mathrm{sec}$ on and $30 \mathrm{sec}$ off in 10 cycle increments using a Biorupter (Diadenode) on ice. After 
pelleting debris, protein $\mathrm{G}$ agarose was added and incubated for 1 hour at $4^{\circ} \mathrm{C}$ with rotation for preclearing. For immunoprecipitation, precleared cell lysate was incubated with the indicated antibodies overnight with the rotation at $4^{\circ} \mathrm{C}$, and protein $\mathrm{G}$ agarose was added for the final $2 \mathrm{hrs}$ of incubation. Beads were washed with low salt, high salt, LiCl wash buffer, and chromatin immunocomplex was eluted using elution buffer through incubating at room temperature for 15 minutes. Reverse crosslinks of protein/DNA complexes to free DNA were realized through adding $5 \mathrm{M} \mathrm{NaCl}$ and incubating at $65^{\circ} \mathrm{C}$ overnight. CHIP-sequence and qPCR was performed on DNA purified after treatment with RNase (30 min, $\left.37^{\circ} \mathrm{C}\right)$ and proteinase $\mathrm{K}\left(2 \mathrm{~h}, 55^{\circ} \mathrm{C}\right)$ after reversal of crosslinks.

\section{RT-PCR and qRT-PCR}

RT-PCR and qRT-PCR were performed according to our previous methods (Su et al, 2014). Total RNA was extracted from the cells, tissues and organs using TRIzol reagent (Invitrogen). First-strand CDNA was generated from total RNA using oligo-dT primers and reverse transcriptase (Invitrogen Corp). The PCR products were visualized on $1.0 \%$ (wt/vol) agarose gels. Quantitative real-time PCR (qRT-PCR) was conducted using QuantiTect SYBR Green PCR Master Mix (Qiagen) and specific primers in an ABI Prism 7000 analyzer (Applied Biosystems). GAPDH mRNA expression was detected in each experimental sample as an endogenous control. All reactions were run in triplicate..

\section{ELISA}

The concentration of cytokines and IAA in the tissue, cell culture supernatants and sera was measured using ELISA kit.

\section{Statistical analyses}

Student's t-test, one-way analysis of variance and the Mann-Whitney $\mathrm{U}$ test were used to determine significance. A 95\% confidence interval was considered significant and was defined as $p<0.05$.

\section{Declarations}

\section{Ethic approval and consent to participate consent for publication}

This study was conducted with approval from the Institutional Review Board at Nankai University, Tianjin Union Medical Center and Tianjin First Central Hospital. Participants were recruited from the health screening centers of Tianjin Union Medical Center and Tianjin First Central Hospital. All participants provided written informed consent.

\section{Data availability}

RAW16s rRNA gene sequence data: BioProject, PRJNA695415;

http://www.ncbi.nlm.nih.gov/bioproject/695415.

\section{Competing interests}


The authors declare no conflict of interest.

\section{Funding}

This research was supported by NSFC grants (grant number 91842302, 81970488, 81970457 and 91629102); The Tianjin Science and Technology Commission (grant number, 20JCQNJC01780 and 18JCZDJC35300); A Ministry of Science and Technology (grant number, 2016YFC1303604); The State Key Laboratory of Medicinal Chemical Biology and the Fundamental Research Funds for the Central University, Nankai university (63191724).

\section{Author contributions}

RY designed the research and wrote the paper; $\mathrm{X} S \mathrm{~S}$ conducted in vivo and in vitro experiments and immunoassays for mechanism; $\mathrm{HQ}, \mathrm{HY}$, mainly conducted in vivo and in vitro experiments and immunoassays of Reg4 KO and huREG4IECtg mice; X S, HQ and HY participated in study design and performed the statistical analysis; $M Z, J H, Y F, Y W$ and $P G$ collected and offered human samples. YY, QZ and $C Z$ performed partly in vivo and in vitro assay; $Y \mathrm{G}$ made mutated bacteria. $Y Z$ offered assistance for the animal experiments. All authors read and approved the final manuscript.

\section{Acknowledgements}

Not applicable.

\section{Author's information}

${ }^{1}$ Translational Medicine Institute, Affiliated Tianjin Union Medical Center of Nankai University; ${ }^{2}$ State Key Laboratory of Medicinal Chemical Biology, Nankai University, Tianjin 300071, China; ${ }^{3}$ Department of Immunology, Nankai University School of Medicine; Nankai University, Tianjin 300071, China;

${ }^{4}$ Department of Colorectal Surgery, Tianjin Union Medical Center; Nankai University, Tianjin, 300121, China.

\section{References}

1. Wu H J, Ivanov, II, Darce J, Hattori K, Shima T, Umesaki Y, et al. Gut-residing segmented filamentous bacteria drive autoimmune arthritis via T helper 17 cells. Immunity. 2010;32(6):815-27. https://doi.org/10.1016/j.immuni.2010.06.001.

2. Sivan A, Corrales L, Hubert N, Williams J B, Aquino-Michaels K, Earley Z M, et al. Commensal Bifidobacterium promotes antitumor immunity and facilitates anti-PD-L1 efficacy. Science. 2015;350(6264):1084-9. https://doi.org/10.1126/science.aac4255.

3. Atarashi K, Tanoue T, Oshima K, Suda W, Nagano Y, Nishikawa H, et al. Treg induction by a rationally selected mixture of Clostridia strains from the human microbiota. Nature. 2013;500(7461):232-6. https://doi.org/10.1038/nature12331. 
4. Dalile B, Van Oudenhove L, Vervliet B, Verbeke K. The role of short-chain fatty acids in microbiota-gutbrain communication. Nat Rev Gastroenterol Hepatol. 2019;16(8):461-78. https://doi.org/10.1038/s41575-019-0157-3.

5. Backhed F, Ley R E, Sonnenburg J L, Peterson D A, Gordon J I. Host-bacterial mutualism in the human intestine. Science. 2005;307(5717):1915-20. https://doi.org/10.1126/science.1104816.

6. Turnbaugh P J, Ley R E, Mahowald M A, Magrini V, Mardis E R, Gordon J I. An obesity-associated gut microbiome with increased capacity for energy harvest. Nature. 2006;444(7122):1027-31. https://doi.org/10.1038/nature05414.

7. Natividad J M, Agus A, Planchais J, Lamas B, Jarry A C, Martin R, et al. Impaired Aryl Hydrocarbon Receptor Ligand Production by the Gut Microbiota Is a Key Factor in Metabolic Syndrome. Cell Metab. 2018;28(5):737-49 e4. https://doi.org/10.1016/j.cmet.2018.07.001.

8. Zelante T, lannitti R G, Cunha C, De Luca A, Giovannini G, Pieraccini G, et al. Tryptophan catabolites from microbiota engage aryl hydrocarbon receptor and balance mucosal reactivity via interleukin-22. Immunity. 2013;39(2):372-85. https://doi.org/10.1016/j.immuni.2013.08.003.

9. Yang W, Yu T, Huang X, Bilotta A J, Xu L, Lu Y, et al. Intestinal microbiota-derived short-chain fatty acids regulation of immune cell IL-22 production and gut immunity. Nat Commun. 2020;11(1):4457. https://doi.org/10.1038/s41467-020-18262-6.

10. Arpaia N, Campbell C, Fan X, Dikiy S, van der Veeken J, deRoos P, et al. Metabolites produced by commensal bacteria promote peripheral regulatory T-cell generation. Nature. 2013;504(7480):451-5. https://doi.org/10.1038/nature12726.

11. Song X, Sun X, Oh S F, Wu M, Zhang Y, Zheng W, et al. Microbial bile acid metabolites modulate gut RORgamma(+) regulatory T cell homeostasis. Nature. 2020;577(7790):410-5. https://doi.org/10.1038/s41586-019-1865-0.

12. Sefik E, Geva-Zatorsky N, Oh S, Konnikova L, Zemmour D, McGuire A M, et al. MUCOSAL IMMUNOLOGY. Individual intestinal symbionts induce a distinct population of RORgamma(+) regulatory T cells. Science. 2015;349(6251):993-7. https://doi.org/10.1126/science.aaa9420.

13. Fagarasan S, Muramatsu M, Suzuki K, Nagaoka H, Hiai H, Honjo T. Critical roles of activationinduced cytidine deaminase in the homeostasis of gut flora. Science. 2002;298(5597):1424-7. https://doi.org/10.1126/science.1077336.

14. Lundell A C, Bjornsson V, Ljung A, Ceder M, Johansen S, Lindhagen G, et al. Infant B cell memory differentiation and early gut bacterial colonization. J Immunol. 2012;188(9):4315-22. https://doi.org/10.4049/jimmunol.1103223.

15. Piper C J M, Rosser E C, Oleinika K, Nistala K, Krausgruber T, Rendeiro A F, et al. Aryl Hydrocarbon Receptor Contributes to the Transcriptional Program of IL-10-Producing Regulatory B Cells. Cell Rep. 2019;29(7):1878-92 e7. https://doi.org/10.1016/j.celrep.2019.10.018.

16. Shen P, Roch T, Lampropoulou V, O'Connor R A, Stervbo U, Hilgenberg E, et al. IL-35-producing B cells are critical regulators of immunity during autoimmune and infectious diseases. Nature. 2014;507(7492):366-70. https://doi.org/10.1038/nature12979. 
17. Vignali D A, Kuchroo V K. IL-12 family cytokines: immunological playmakers. Nat Immunol. 2012;13(8):722-8. https://doi.org/10.1038/ni.2366.

18. Wang R X, Yu C R, Dambuza I M, Mahdi R M, Dolinska M B, Sergeev $Y$ V, et al. Interleukin-35 induces regulatory B cells that suppress autoimmune disease. Nat Med. 2014;20(6):633-41. https://doi.org/10.1038/nm.3554.

19. Dambuza I M, He C, Choi J K, Yu C R, Wang R, Mattapallil M J, et al. IL-12p35 induces expansion of IL-10 and IL-35-expressing regulatory B cells and ameliorates autoimmune disease. Nat Commun. 2017;8(1):719. https://doi.org/10.1038/s41467-017-00838-4.

20. Devergne O, Birkenbach M, Kieff E. Epstein-Barr virus-induced gene 3 and the p35 subunit of interleukin 12 form a novel heterodimeric hematopoietin. Proc Natl Acad Sci U S A. 1997;94(22):12041-6. https://doi.org/10.1073/pnas.94.22.12041.

21. Bettini M, Castellaw A H, Lennon G P, Burton A R, Vignali D A. Prevention of autoimmune diabetes by ectopic pancreatic beta-cell expression of interleukin-35. Diabetes. 2012;61(6):1519-26. https://doi.org/10.2337/db11-0784.

22. Huang C H, Loo E X, Kuo I C, Soh G H, Goh D L, Lee B W, et al. Airway inflammation and IgE production induced by dust mite allergen-specific memory/effector Th2 cell line can be effectively attenuated by IL-35. J Immunol. 2011;187(1):462-71. https://doi.org/10.4049/jimmunol.1100259.

23. Zhang J, Lin Y, Li C, Zhang X, Cheng L, Dai L, et al. IL-35 Decelerates the Inflammatory Process by Regulating Inflammatory Cytokine Secretion and M1/M2 Macrophage Ratio in Psoriasis. J Immunol. 2016;197(6):2131-44. https://doi.org/10.4049/jimmunol.1600446.

24. Sawant D V, Yano H, Chikina M, Zhang Q, Liao M, Liu C, et al. Adaptive plasticity of IL-10(+) and IL35(+) Treg cells cooperatively promotes tumor T cell exhaustion. Nat Immunol. 2019;20(6):724-35. https://doi.org/10.1038/s41590-019-0346-9.

25. Chen $C$, Xu H, Peng Y, Luo H, Huang G X, Wu X J, et al. Elevation in the counts of IL-35-producing B cells infiltrating into lung tissue in mycobacterial infection is associated with the downregulation of Th1/Th17 and upregulation of Foxp3(+)Treg. Sci Rep. 2020;10(1):13212. https://doi.org/10.1038/s41598-020-69984-y.

26. Su L C, Liu X Y, Huang A F, Xu W D. Emerging role of IL-35 in inflammatory autoimmune diseases. Autoimmun Rev. 2018;17(7):665-73. https://doi.org/10.1016/j.autrev.2018.01.017.

27. Tedder T F, Leonard W J. Autoimmunity: regulatory B cells-IL-35 and IL-21 regulate the regulators. Nat Rev Rheumatol. 2014;10(8):452-3. https://doi.org/10.1038/nrrheum.2014.95.

28. Olson B M, Jankowska-Gan E, Becker J T, Vignali D A, Burlingham W J, McNeel D G. Human prostate tumor antigen-specific CD8+ regulatory T cells are inhibited by CTLA-4 or IL-35 blockade. J Immunol. 2012;189(12):5590-601. https://doi.org/10.4049/jimmunol.1201744.

29. Dixon K O, van der Kooij S W, Vignali D A, van Kooten C. Human tolerogenic dendritic cells produce IL35 in the absence of other IL-12 family members. Eur J Immunol. 2015;45(6):1736-47. https://doi.org/10.1002/eji.201445217. 
30. Schroder N, Sekhar A, Geffers I, Muller J, Dittrich-Breiholz O, Kracht M, et al. Identification of mouse genes with highly specific expression patterns in differentiated intestinal epithelium. Gastroenterology. 2006;130(3):902-7. https://doi.org/10.1053/j.gastro.2005.12.025.

31. Heiskala K, Arola J, Heiskala M, Andersson L C. Expression of Reg IV and Hath1 in neuroendocrine neoplasms. Histol Histopathol. 2010;25(1):63-72. https://doi.org/10.14670/HH-25.63.

32. Oue N, Mitani Y, Aung P P, Sakakura C, Takeshima Y, Kaneko M, et al. Expression and localization of Reg IV in human neoplastic and non-neoplastic tissues: Reg IV expression is associated with intestinal and neuroendocrine differentiation in gastric adenocarcinoma. J Pathol. 2005;207(2):18598. https://doi.org/10.1002/path.1827.

33. Ho M R, Lou Y C, Wei S Y, Luo S C, Lin W C, Lyu P C, et al. Human RegIV protein adopts a typical Ctype lectin fold but binds mannan with two calcium-independent sites. J Mol Biol. 2010;402(4):68295. https://doi.org/10.1016/j.jmb.2010.07.061.

34. Vaishnava S, Yamamoto M, Severson K M, Ruhn K A, Yu X, Koren O, et al. The antibacterial lectin Reglllgamma promotes the spatial segregation of microbiota and host in the intestine. Science. 2011;334(6053):255-8. https://doi.org/10.1126/science.1209791.

35. Qi H, Wei J, Gao Y, Yang Y, Li Y, Zhu H, et al. Reg4 and complement factor D prevent the overgrowth of E. coli in the mouse gut. Commun Biol. 2020;3(1):483. https://doi.org/10.1038/s42003-020-01219-2.

36. Cani P D, Amar J, Iglesias M A, Poggi M, Knauf C, Bastelica D, et al. Metabolic endotoxemia initiates obesity and insulin resistance. Diabetes. 2007;56(7):1761-72. https://doi.org/10.2337/db06-1491.

37. Cox L M, Blaser M J. Antibiotics in early life and obesity. Nat Rev Endocrinol. 2015;11(3):182-90. https://doi.org/10.1038/nrendo.2014.210.

38. Arthur J C, Perez-Chanona E, Muhlbauer M, Tomkovich S, Uronis J M, Fan T J, et al. Intestinal inflammation targets cancer-inducing activity of the microbiota. Science. 2012;338(6103):120-3. https://doi.org/10.1126/science.1224820.

39. Stolarczyk E. Adipose tissue inflammation in obesity: a metabolic or immune response? Curr Opin Pharmacol. 2017;37(35-40. https://doi.org/10.1016/j.coph.2017.08.006.

40. Lee B C, Lee J. Cellular and molecular players in adipose tissue inflammation in the development of obesity-induced insulin resistance. Biochim Biophys Acta. 2014;1842(3):446-62. https://doi.org/10.1016/j.bbadis.2013.05.017.

41. Collison L W, Chaturvedi V, Henderson A L, Giacomin P R, Guy C, Bankoti J, et al. IL-35-mediated induction of a potent regulatory T cell population. Nat Immunol. 2010;11(12):1093-101. https://doi.org/10.1038/ni.1952.

42. Collison L W, Workman C J, Kuo T T, Boyd K, Wang Y, Vignali K M, et al. The inhibitory cytokine IL-35 contributes to regulatory T-cell function. Nature. 2007;450(7169):566-9. https://doi.org/10.1038/nature06306.

43. Winer D A, Winer S, Shen L, Wadia P P, Yantha J, Paltser G, et al. B cells promote insulin resistance through modulation of T cells and production of pathogenic IgG antibodies. Nat Med. 2011;17(5):610-7. https://doi.org/10.1038/nm.2353. 
44. Virdi V, Coddens A, De Buck S, Millet S, Goddeeris B M, Cox E, et al. Orally fed seeds producing designer IgAs protect weaned piglets against enterotoxigenic Escherichia coli infection. Proc Natl Acad Sci U S A. 2013;110(29):11809-14. https://doi.org/10.1073/pnas.1301975110.

45. Xiao Y, Lu Y, Wang Y, Yan W, Cai W. Deficiency in intestinal epithelial Reg4 ameliorates intestinal inflammation and alters the colonic bacterial composition. Mucosal Immunol. 2019;12(4):919-29. https://doi.org/10.1038/s41385-019-0161-5.

46. Cani P D, Bibiloni R, Knauf C, Waget A, Neyrinck A M, Delzenne N M, et al. Changes in gut microbiota control metabolic endotoxemia-induced inflammation in high-fat diet-induced obesity and diabetes in mice. Diabetes. 2008;57(6):1470-81. https://doi.org/10.2337/db07-1403.

47. Shi H, Kokoeva M V, Inouye K, Tzameli I, Yin H, Flier J S. TLR4 links innate immunity and fatty acidinduced insulin resistance. J Clin Invest. 2006;116(11):3015-25. https://doi.org/10.1172/JCI28898.

48. Tian Y. Epigenetic regulation of pregnane X receptor activity. Drug Metab Rev. 2013;45(2):166-72. https://doi.org/10.3109/03602532.2012.756012.

49. Ryu A H, Eckalbar W L, Kreimer A, Yosef N, Ahituv N. Use antibiotics in cell culture with caution: genome-wide identification of antibiotic-induced changes in gene expression and regulation. Sci Rep. 2017;7(1):7533. https://doi.org/10.1038/s41598-017-07757-w.

50. Squires E J, Sueyoshi T, Negishi M. Cytoplasmic localization of pregnane $X$ receptor and liganddependent nuclear translocation in mouse liver. J Biol Chem. 2004;279(47):49307-14. https://doi.org/10.1074/jbc.M407281200.

51. van de Winkel $A$, van Zoest $K$ P, van Dekken $H$, Moons $L$ M, Kuipers E J, van der Laan L J. Differential expression of the nuclear receptors farnesoid $X$ receptor $(F X R)$ and pregnane $X$ receptor (PXR) for grading dysplasia in patients with Barrett's oesophagus. Histopathology. 2011;58(2):246-53. https://doi.org/10.1111/j.1365-2559.2011.03743.x.

52. Wei P, Zhang J, Dowhan D H, Han Y, Moore D D. Specific and overlapping functions of the nuclear hormone receptors CAR and PXR in xenobiotic response. Pharmacogenomics J. 2002;2(2):117-26. https://doi.org/10.1038/sj.tpj.6500087.

53. Handschin C, Meyer U A. Induction of drug metabolism: the role of nuclear receptors. Pharmacol Rev. 2003;55(4):649-73. https://doi.org/10.1124/pr.55.4.2.

54. Makki K, Deehan E C, Walter J, Backhed F. The Impact of Dietary Fiber on Gut Microbiota in Host Health and Disease. Cell Host Microbe. 2018;23(6):705-15.

https://doi.org/10.1016/j.chom.2018.05.012.

55. Cani P D, Jordan B F. Gut microbiota-mediated inflammation in obesity: a link with gastrointestinal cancer. Nat Rev Gastroenterol Hepatol. 2018;15(11):671-82. https://doi.org/10.1038/s41575-0180025-6.

56. Crovesy L, Ostrowski M, Ferreira D, Rosado E L, Soares-Mota M. Effect of Lactobacillus on body weight and body fat in overweight subjects: a systematic review of randomized controlled clinical trials. Int J Obes (Lond). 2017;41(11):1607-14. https://doi.org/10.1038/ijo.2017.161. 
57. Rosser E C, Oleinika K, Tonon S, Doyle R, Bosma A, Carter N A, et al. Regulatory B cells are induced by gut microbiota-driven interleukin-1 beta and interleukin-6 production. Nat Med. 2014;20(11):1334-9. https://doi.org/10.1038/nm.3680.

58. Zhang Y, Li J, Zhou N, Zhang Y, Wu M, Xu J, et al. The Unknown Aspect of BAFF: Inducing IL-35 Production by a CD5(+)CD1d(hi)FcgammaRIlb(hi) Regulatory B-Cell Subset in Lupus. J Invest Dermatol. 2017;137(12):2532-43. https://doi.org/10.1016/j.jid.2017.07.843.

59. Yu C R, Choi J K, Uche A N, Egwuagu C E. Production of IL-35 by Bregs is mediated through binding of BATF-IRF-4-IRF-8 complex to il12a and ebi3 promoter elements. J Leukoc Biol. 2018;104(6):114757. https://doi.org/10.1002/JLB.3A0218-071RRR.

60. Wetzel A, Scholtka B, Gerecke C, Kleuser B. Epigenetic histone modulation contributes to improvements in inflammatory bowel disease via EBI3. Cell Mol Life Sci. 2020;77(23):5017-30. https://doi.org/10.1007/s00018-020-03451-9.

61. Collison L W, Delgoffe G M, Guy C S, Vignali K M, Chaturvedi V, Fairweather D, et al. The composition and signaling of the IL-35 receptor are unconventional. Nat Immunol. 2012;13(3):290-9. https://doi.org/10.1038/ni.2227.

62. Roager H M, Licht T R. Microbial tryptophan catabolites in health and disease. Nat Commun. 2018;9(1):3294. https://doi.org/10.1038/s41467-018-05470-4.

63. Venkatesh M, Mukherjee S, Wang H, Li H, Sun K, Benechet A P, et al. Symbiotic bacterial metabolites regulate gastrointestinal barrier function via the xenobiotic sensor PXR and Toll-like receptor 4. Immunity. 2014;41(2):296-310. https://doi.org/10.1016/j.immuni.2014.06.014.

64. Lamas B, Richard M L, Leducq V, Pham H P, Michel M L, Da Costa G, et al. CARD9 impacts colitis by altering gut microbiota metabolism of tryptophan into aryl hydrocarbon receptor ligands. Nat Med. 2016;22(6):598-605. https://doi.org/10.1038/nm.4102.

65. Shizu R, Benoki S, Numakura Y, Kodama S, Miyata M, Yamazoe Y, et al. Xenobiotic-induced hepatocyte proliferation associated with constitutive active/androstane receptor (CAR) or peroxisome proliferator-activated receptor alpha (PPARalpha) is enhanced by pregnane $\mathrm{X}$ receptor (PXR) activation in mice. PLoS One. 2013;8(4):e61802. https://doi.org/10.1371/journal.pone.0061802.

66. Qiu Z, Cervantes J L, Cicek B B, Mukherjee S, Venkatesh M, Maher L A, et al. Pregnane X Receptor Regulates Pathogen-Induced Inflammation and Host Defense against an Intracellular Bacterial Infection through Toll-like Receptor 4. Sci Rep. 2016;6(31936. https://doi.org/10.1038/srep31936.

67. Cui J Y, Klaassen C D. RNA-Seq reveals common and unique PXR- and CAR-target gene signatures in the mouse liver transcriptome. Biochim Biophys Acta. 2016;1859(9):1198-217. https://doi.org/10.1016/j.bbagrm.2016.04.010.

68. Wang L, Zhu S, Xu G, Feng J, Han T, Zhao F, et al. Gene Expression and Antiviral Activity of Interleukin-35 in Response to Influenza A Virus Infection. J Biol Chem. 2016;291(32):16863-76. https://doi.org/10.1074/jbc.M115.693101. 
69. Wilck N, Matus M G, Kearney S M, Olesen S W, Forslund K, Bartolomaeus H, et al. Salt-responsive gut commensal modulates TH17 axis and disease. Nature. 2017;551(7682):585-9. https://doi.org/10.1038/nature24628.

\section{Figures}

a

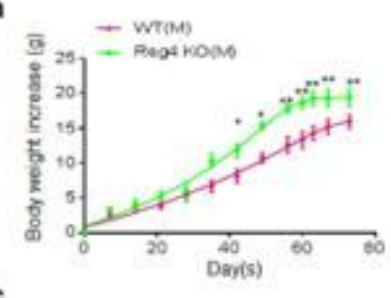

c

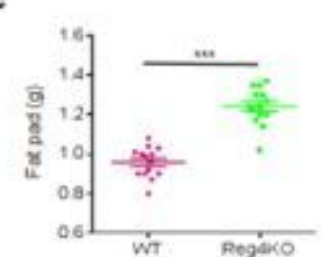

e

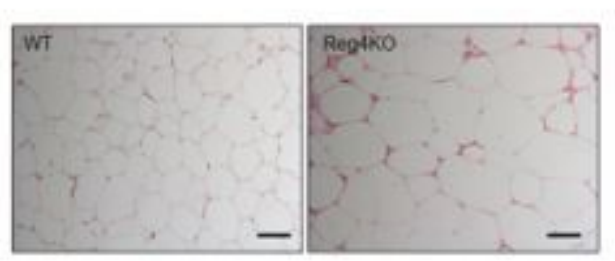

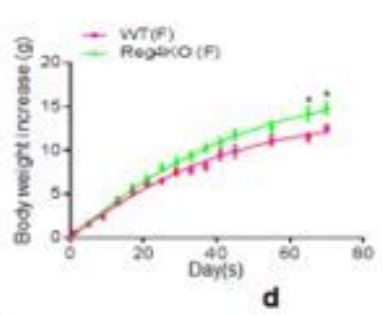

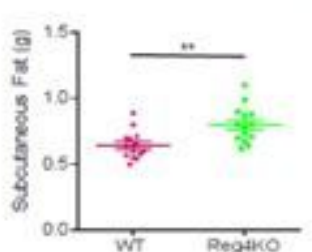

d
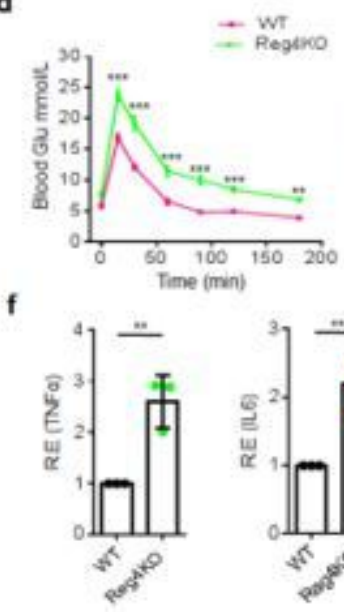

h

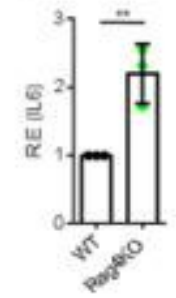

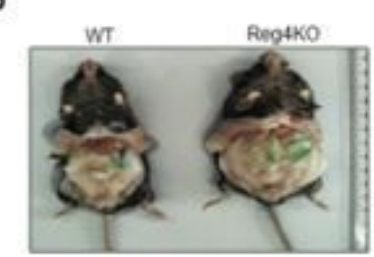
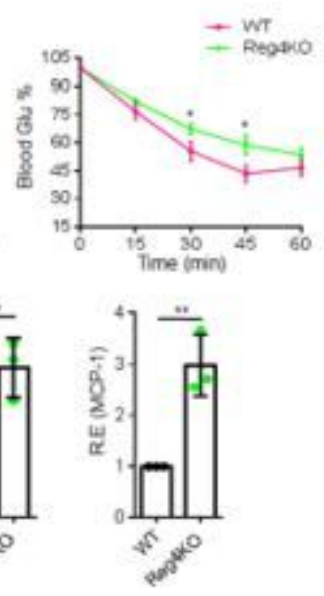

g
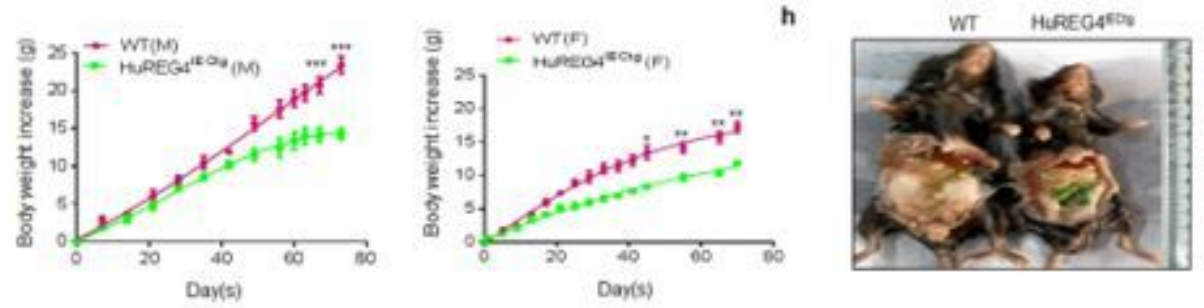

i
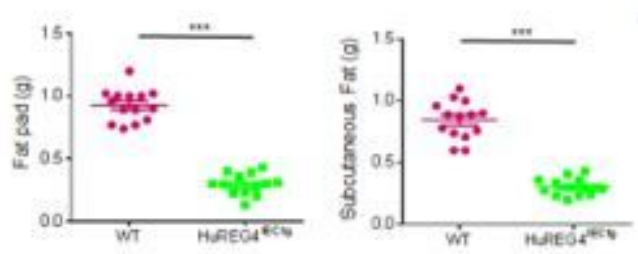

k
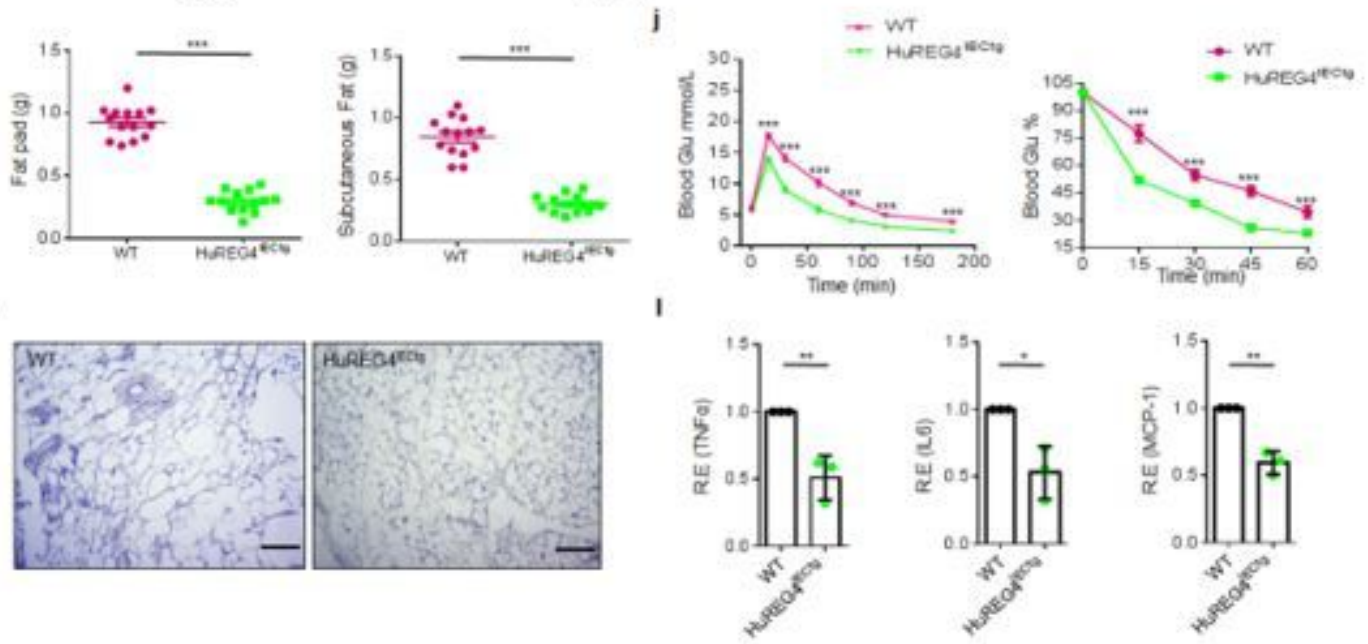

Figure 1 
Reg4 promotes resistance to high-fat diet induced obesity. a Body weight increases of male (right) or female (left) WT and Reg4 KO mice fed high-fat diet (HFD) ( $n=14)$. These mice are no differences at baseline before feeding HFD. b Typical phenotype of male WT and Reg4 KO mice fed HFD for three months. One representative of 42 mice. c Fat pad weights of WT and Reg4KO mice fed HFD. d Glucose tolerance and insulin sensitivity of WT and Reg4 KO mice fed HFD for three months $(n=6)$. e H/E staining of adipose tissues of WT and Reg4 KO mice fed HFD. One representative of 14 mice. $f$ qRT-PCR of TNFa, IL- 6 and MCP1 in the mixed adipose tissues of WT and Reg4 KO mice fed HFD ( $n=14)$. g Body weight increases of male (right) and female (left) WT and huREG4IECtg mice fed HFD $(n=14)$. These mice are no differences at baseline before feeding HFD. h Typical phenotype of male WT and huREG4IECtg mice fed HFD for three months. One representative of 42 mice. i Fat pad weights of WT and huREG4IECtg mice fed HFD. j Glucose tolerance and insulin sensitivity of WT and huREG4IECtg mice fed HFD $(n=6) . \mathrm{kH} / \mathrm{E}$ staining of adipose tissues of WT and huREG4IECtg mice fed HFD. One representative of 14 mice. I qRTPCR of TNFa, IL- 6 and MCP1 in the mixed adipose tissues of WT and Reg4 KO mice fed HFD $(n=14)$. Scale bars $=40 \mu \mathrm{m} \otimes$ Analysis of variance test in $a, d, g$ and $j$; Student's t-test in other panels, mean $\pm S D$. Data are a representative of three independent experiments; $R$. E, relative expression. ${ }^{\star} P<0.05,{ }^{*} P<0.01$, and $* * * P<0.001$. 
a
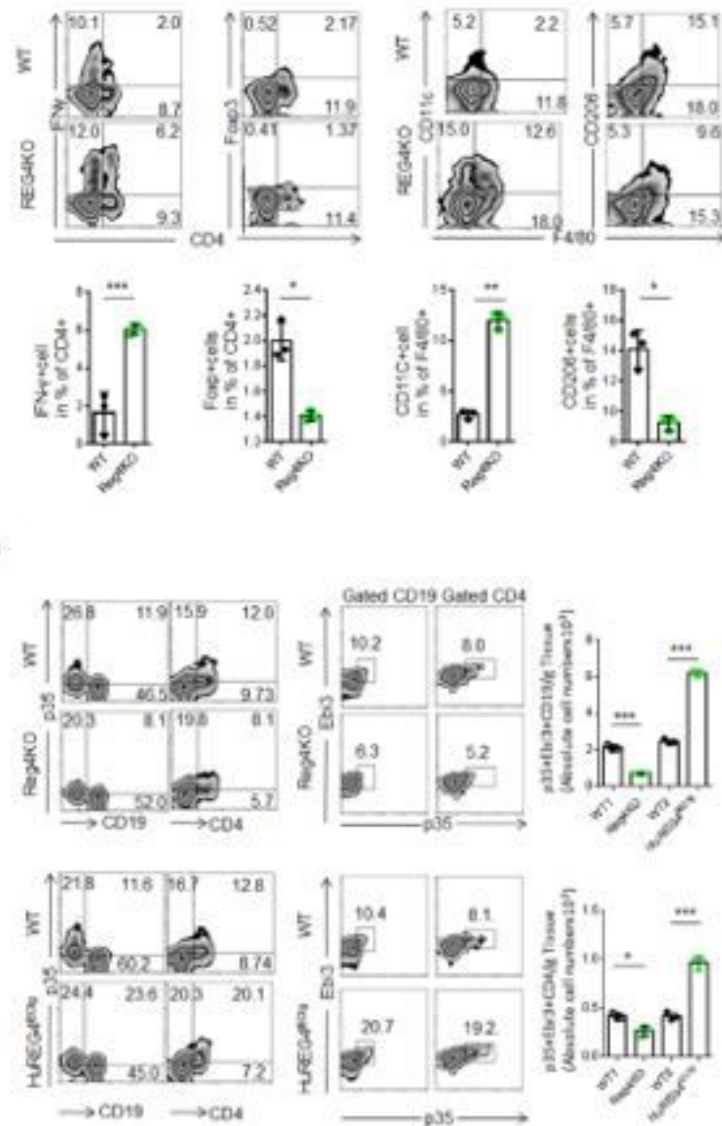

b
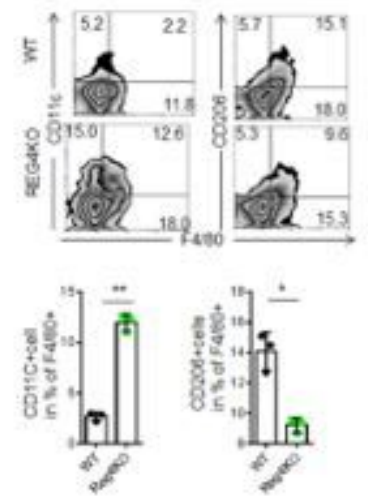
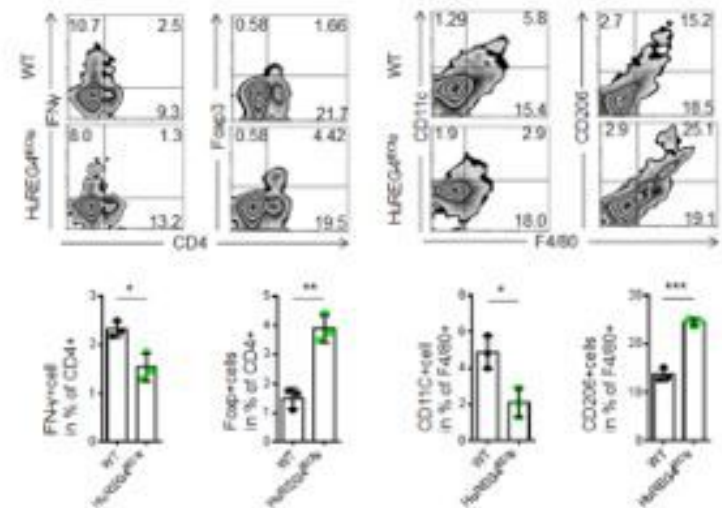

d
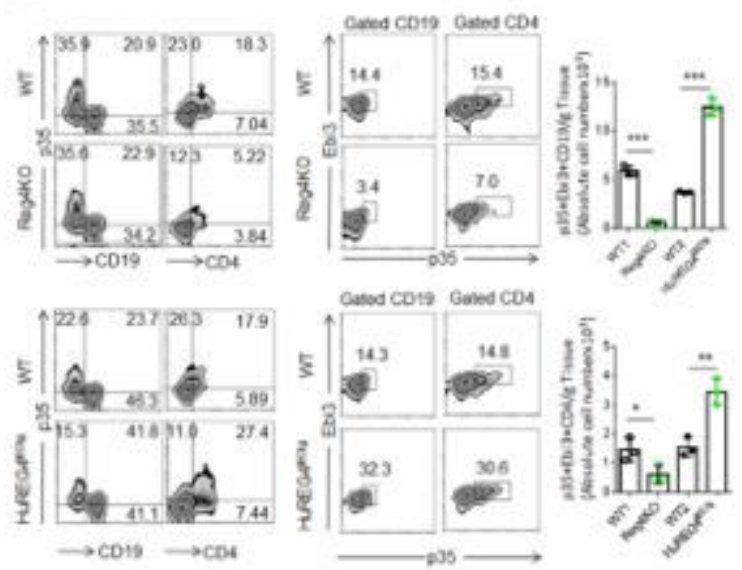
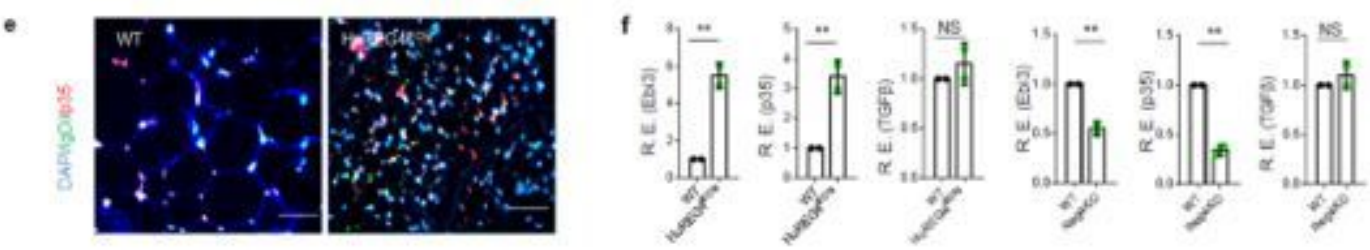

g
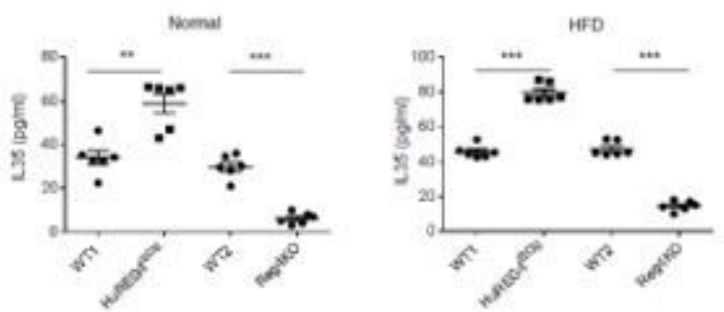

\section{Figure 2}

Reg 4 promotes accumulation of IL-35+ cells in adipose tissues. a Flow cytometry of IFNy+CD4+, Foxp3+CD4+ $\triangle F 4 / 80+C D 11 C+$ and F4/80+CD206+ cells in the adipose tissues of Reg4 KO and control WT mice fed HFD for three months. b Flow cytometry of IFNy+CD4+, Foxp3+CD4+\$F4/80+CD11C+ and F4/80+CD206+ cells in the adipose tissues of huREG4IECtg and control littermate WT mice fed HFD for three months. c Flow cytometry of p35+CD19+, p35+CD4+\p35+Ebi3+CD19+ and p35+Ebi3+CD4+ cells in the fat pat adipose tissues of Reg4 KO and control WT or huREG4IECtg and their littermate control 
mice fed HFD for three months. d Flow cytometry of p35+CD19+, p35+CD4+Øp35+Ebi3+CD19+ and p35+Ebi3+CD4+ cells in the subcutaneously adipose tissues of Reg4 KO and control WT or huREG4IECtg and their littermate control mice fed HFD for three months. e Immunostaining of IgD+p35+ in the adipose of huREG4IECtg (HuREG4) and control littermate WT mice (WT) fed HFD for three months. $\mathrm{f}$ qRT-PCR of Ebi3, p35 or TGFß in the adipose tissues of WT Reg4 KO, WT and huREG4IECtg or their control littermate WT mice fed HFD for three months (mixed sample from 14 mice). $g$ ELISA of IL-35 in huREG4IECtgD WT(WT1) and Reg4 KO or WT (WT2) mice with (HFD) or without (Normal) feeding HFD for three months. Scale bars $=40 \mu \mathrm{m} \otimes$ Student's t-test in all panels, mean $\pm S D$; Data are a representative of three independent experiments; R. E, relative expression. ${ }^{\star} P<0.05$, ${ }^{\star *} P<0.01$, and ${ }^{* \star * P}<0.001$; NS, No significance. 

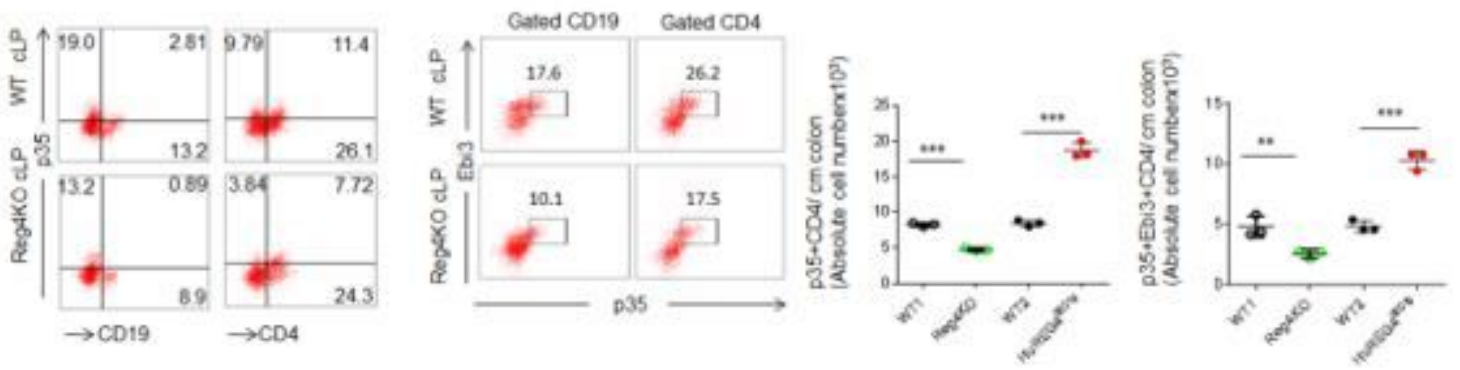

b
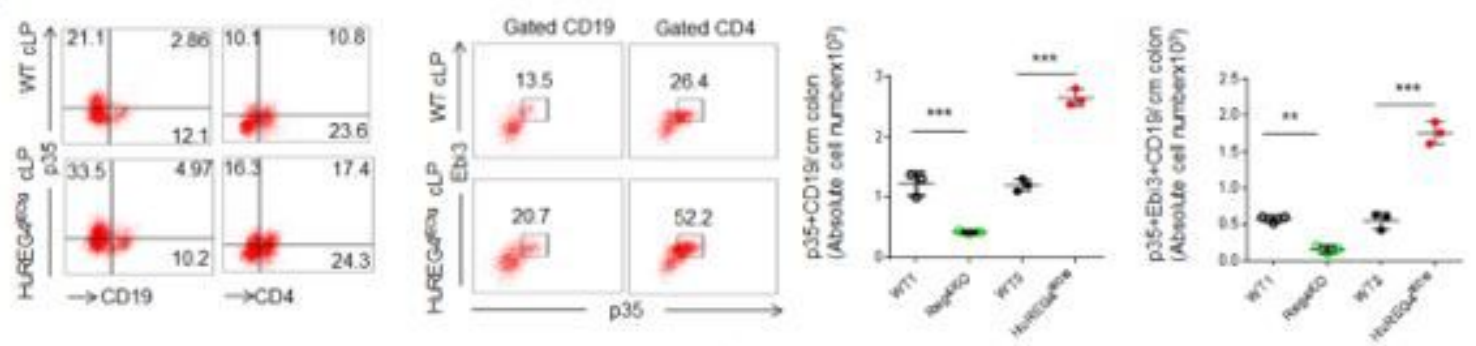

c
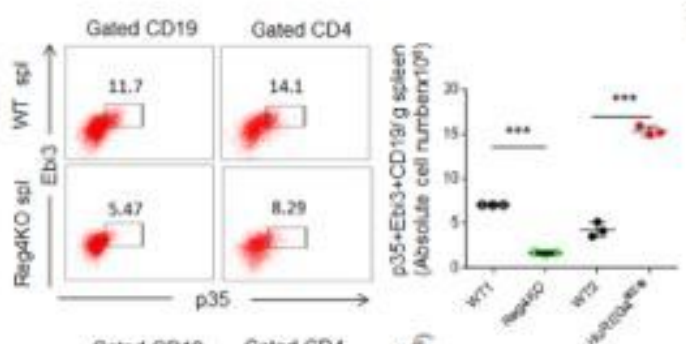

d
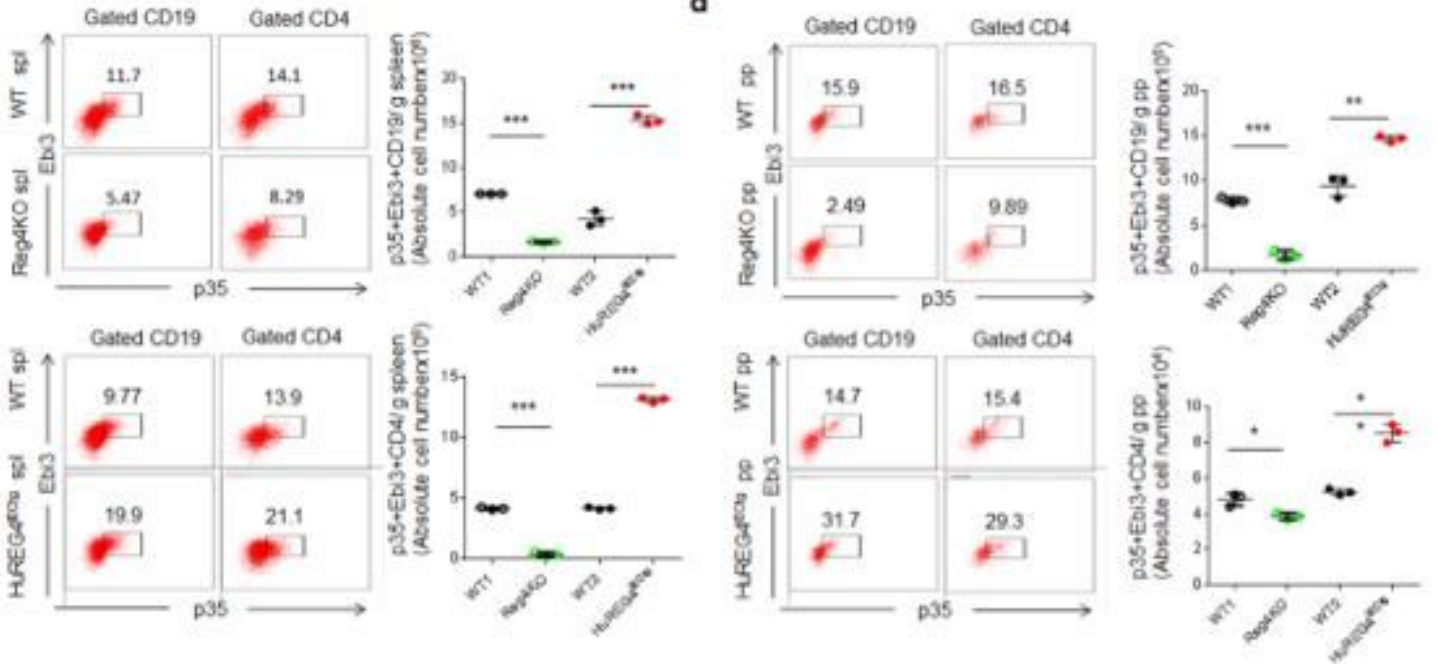

e

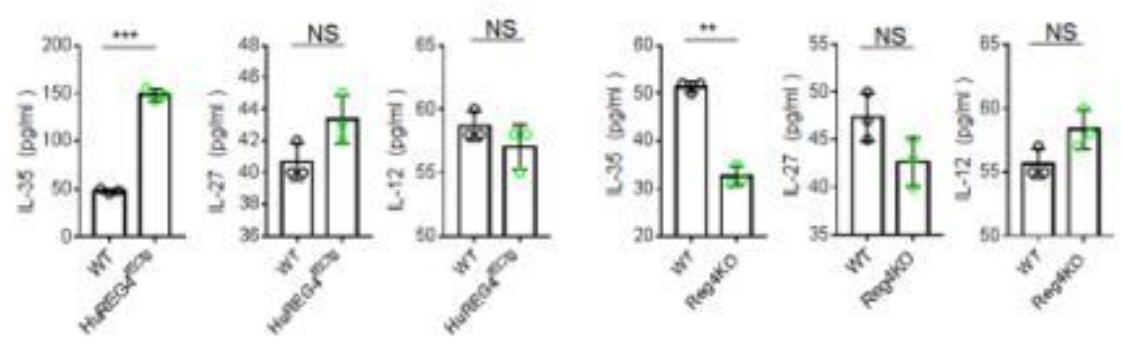

\section{Figure 3}

Reg 4 promotes accumulation of IL-35+ cells in colonic lamina propria (LP) tissues, spleen and payer patch. $a$ and b Flow cytometry of p35+CD19+, p35+CD4+, p35+Ebi3+CD19+ and p35+Ebi3+CD4+ cells in the colonic LP of Reg4 KO and control WT (a) or huREG4IECtg and their littermate control mice (b) fed HFD for three months. $c$ and d Flow cytometry of p35+Ebi3+CD19+ and p35+Ebi3+CD4+ cells in spleen (c) the payer patch (PP) $₫ \mathrm{~d} \rrbracket$ of Reg $4 \mathrm{KO}$ and control WT or huREG4IECtg and their littermate control mice fed HFD for three months. e ELISA of IL-35, IL-27 and IL-12 in colon tissues of Reg4 KO and control WT or 
huREG4IECtg and their littermate control mice fed HFD for three months. Gut tissues was milled in liquid nitrogen and then lysed with non-denatured tissue lysis solution for ELISA. Mixed sample from 12 mice. Student's t-test in all panels, mean $\pm S D$; Data are a representative of three independent experiments. ${ }^{*} \mathrm{P}<$ 0.05 , $* * P<0.01$, and $* \star * P<0.001 ; N S$, No significance.

a
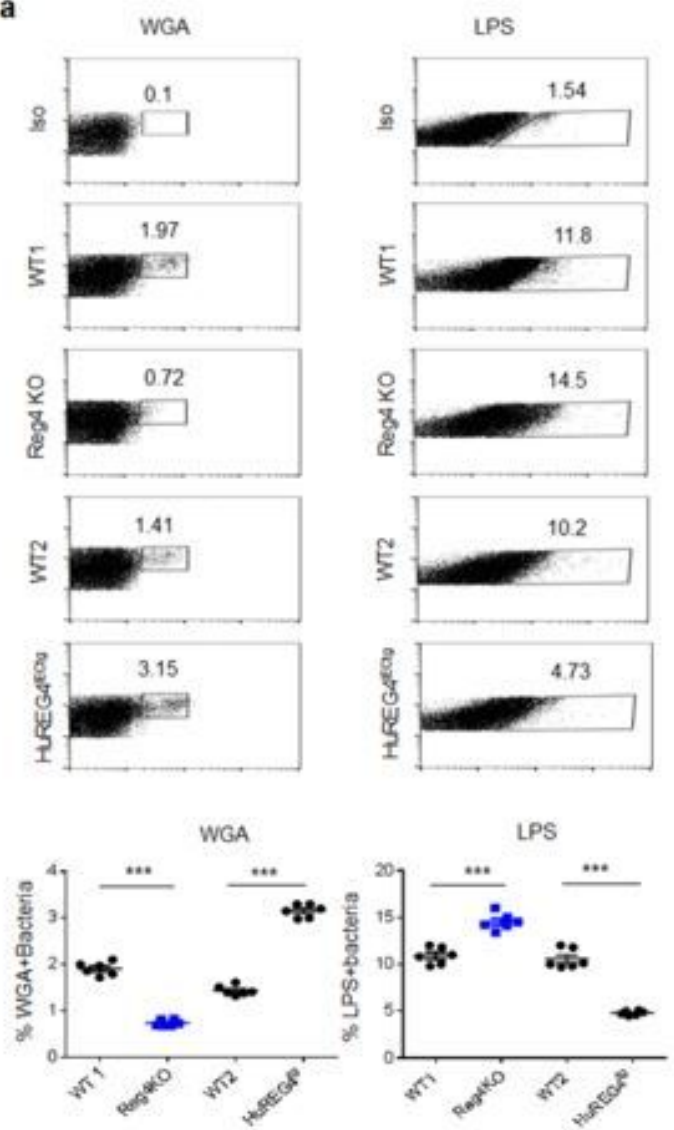

c

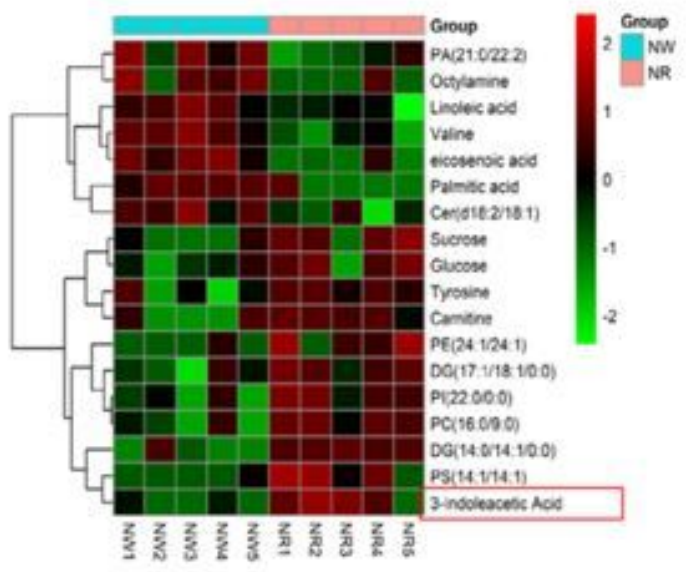

b
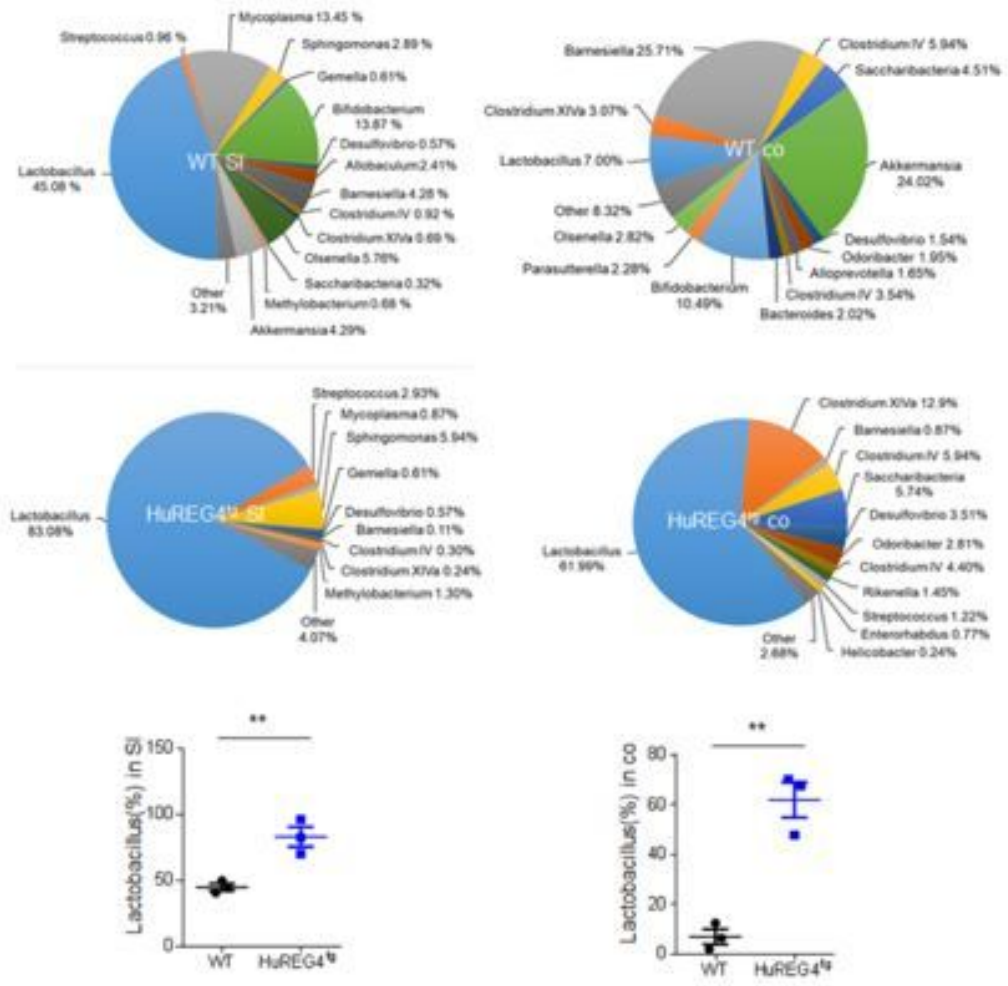

d
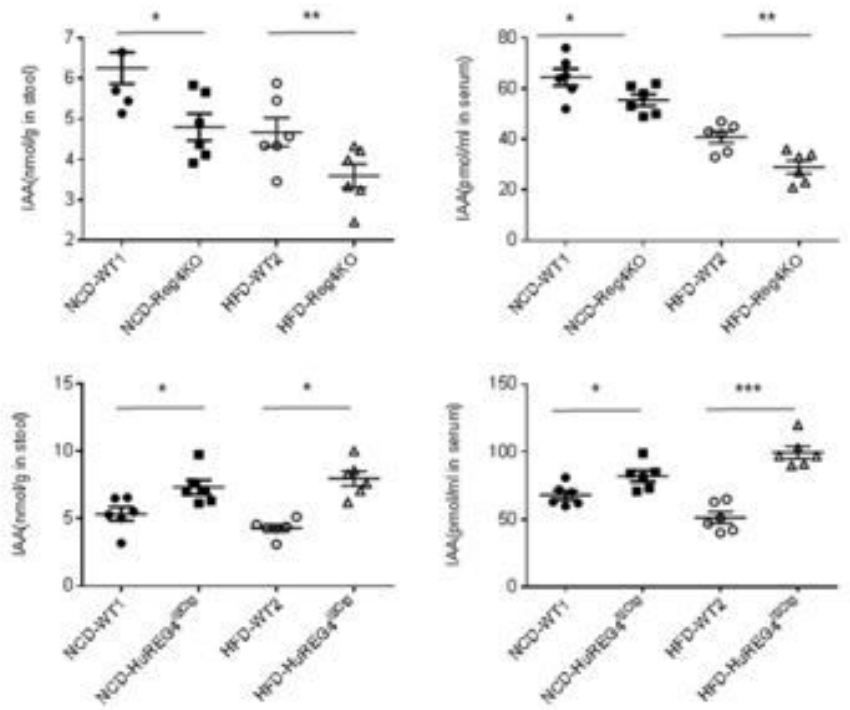

Figure 4 
Reg4 affects composition and metabolites of gut microbiota. a Flow cytometry of WGA+ and LPS+ bacteria in fresh feces of Reg4 KO and control WT (WT1) or huREG4IECtg (HuREG4tg) and their littermate control mice (WT2). b The proportion of gut bacteria after 16S rRNA-seq of gut microbiota from pooled ileum content (S.I) and colon content (Co) samples of WT and huREG4IECtg (HuREG4tg) mice (Three independent experiments, 5 mice (7-8 weeks old, male)/ time/group). c LC-MS/MS analyses of peripheral bloods of huREG4IECtg(NR1-NR5) and their control littermate (NW1-NW5) mice fed normal diet ( $n=5)$. d IAA analyses in the fresh stool and peripheral blood in WT (WT1), Reg4 KO, huREG4IECtg and their control littermate mice (WT2) with (HFD-WT, HFD-Reg4KO or HFD-HuREG4IECtg) or without (NCD-WT, NCDReg4KO or NCD-HuREG4 IECtg) feeding HFD for three months. Student's t-test in all panels, mean $\pm S D$. *P $<0.05, * \star P<0.01$, and $* \star * P<0.001$. 
a

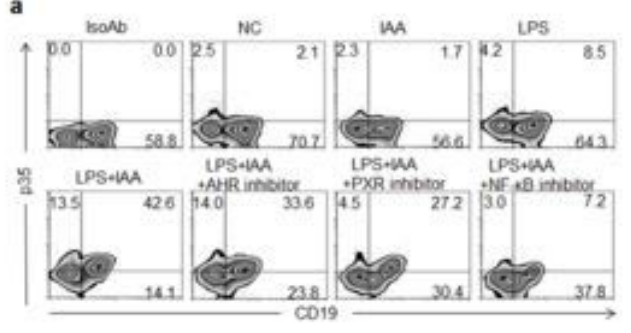

b

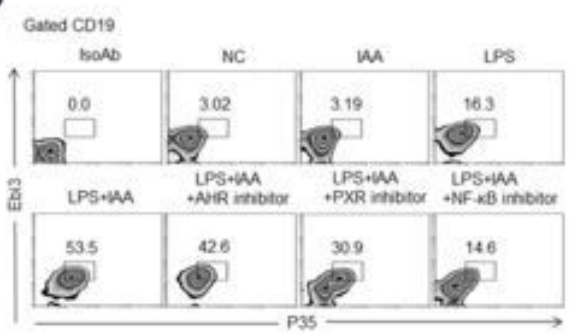

d

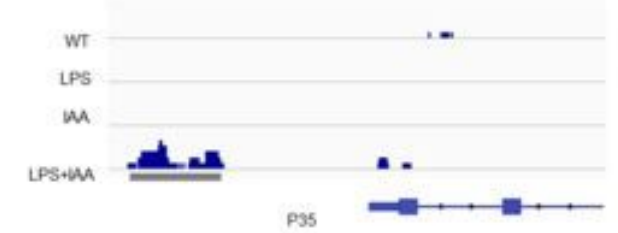

f

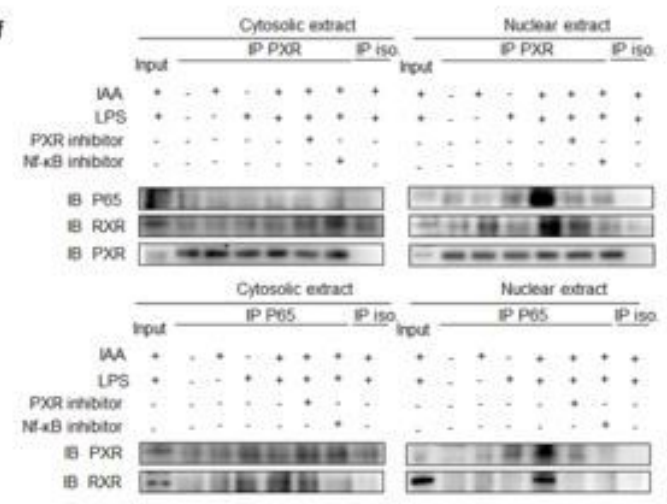

h

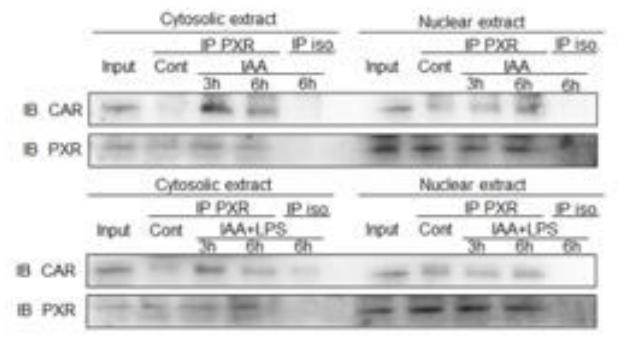

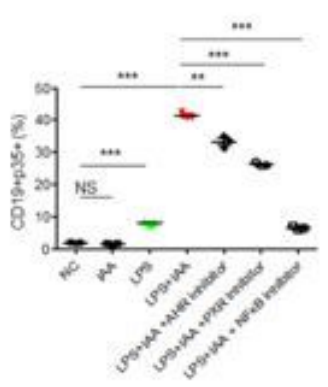
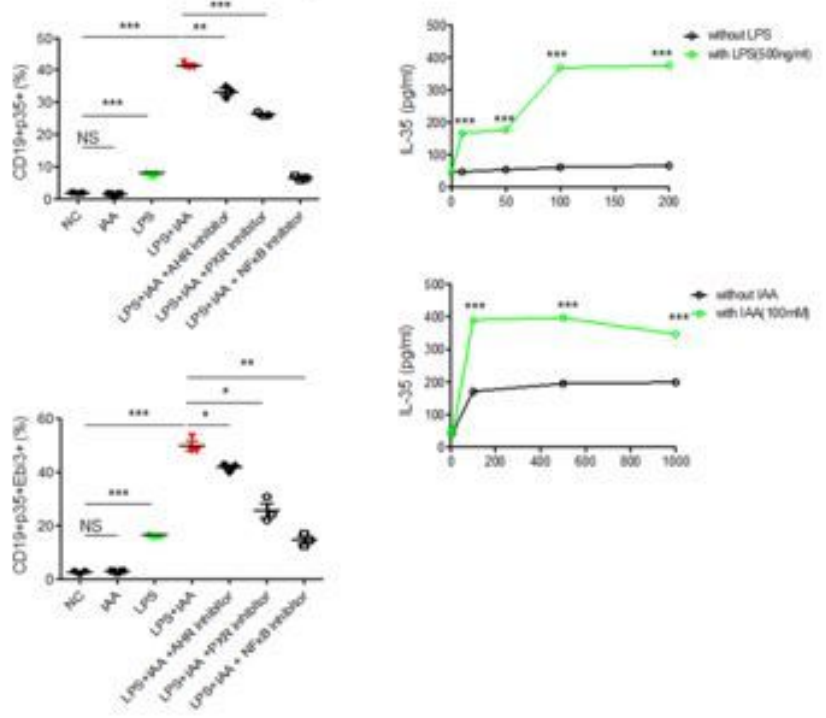

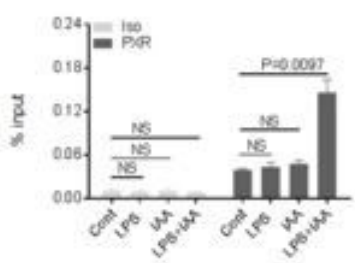

g
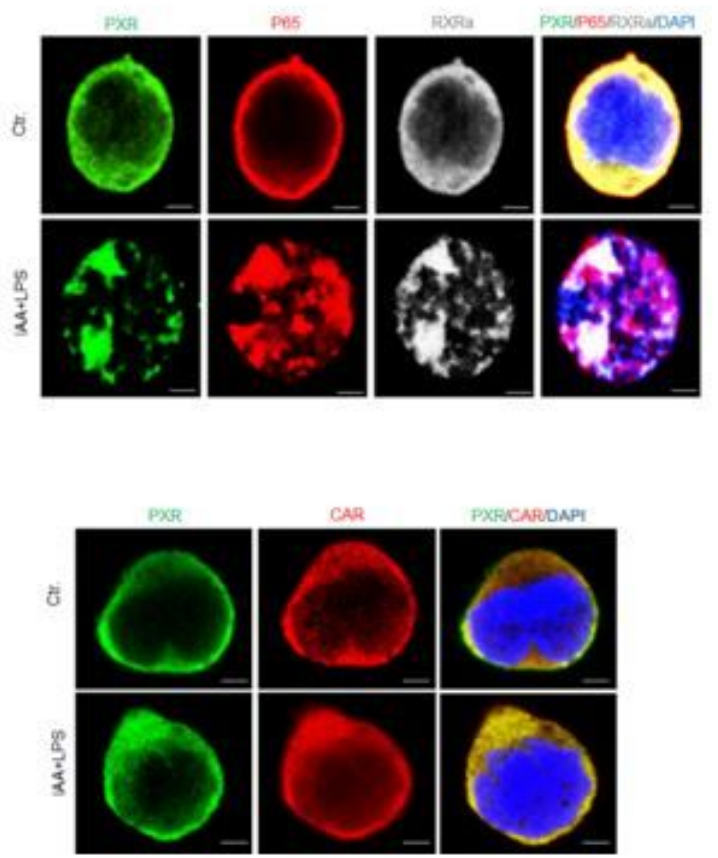

\section{Figure 5}

IAA with LPS promotes binding of PXR with NFkB p65 and RXR. a Flow cytometry of p35+CD19+ cells in the spleen cells after exposed to IAA, LPS, LPS+IAA囚LPS+IAA+AhR inhibitor, LPS+IAA+PXR inhibitor, LPS+IAA+NFkB inhibitor for $24 \mathrm{hrs}$. NC, negative control. b Flow cytometry of p35+Ebi35+CD19+ cells in the spleen cells after exposed to IAA, LPS, LPS+IAA囚LPS+IAA+AHR inhibitor, LPS+IAA+PXR inhibitor, LPS+IAA+NFkB inhibitor for 24 hrs.NC, negative control. c ELISA of IL-35 in the supernatants of spleen 
cells after exposed to different concentration of IAA in the presence of LPS or different concentration of LPS in the presence of IAA. $d$ Chip-sequencing analyses of B lymphocyte line WEHI 231 B cells after exposed different stimulators LPS, IAA or LPS +IAA for 6 hrs. e Chip-PCR of PXR binding site on the promoter region of p35 in the WEHI 231 cells after exposed to different stimulators LPS, IAA or LPS +IAA for 6 hrs. $f$ Immunblotting of p65, RXRa or PXR in the cytosolic or nuclear extract of immunoprecipitation by anti-PXR or anti-p65. Iso, isotypic antibody. $g$ Immunostaining of PXR, p65 and RXRa in the WEHI231 B cells after exposed to IAA+LPS. Ctr., no stimulators. $h$ Immunoblotting of CAR and PXR of cytosolic extracts and nuclear extracts after immunoprecipitation using anti-PXR in the WEHI231 B cells after exposed to IAA or IAA+LPS. i Immunostaining of PXR and CAR in the WEHI231 B cells after exposed to IAA+LPS. Student's t-test in $a, b$ and e, mean $\pm S D$; Analysis of variance test in $c$. ${ }^{*} P<0.05,{ }^{\star *} P<0.01$, and ${ }^{\star \star \star} \mathrm{P}<0.001$, NS; No significance. 
a

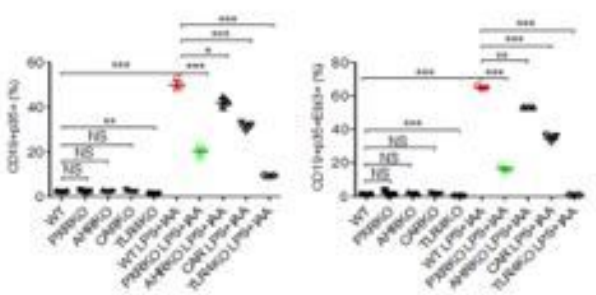

b
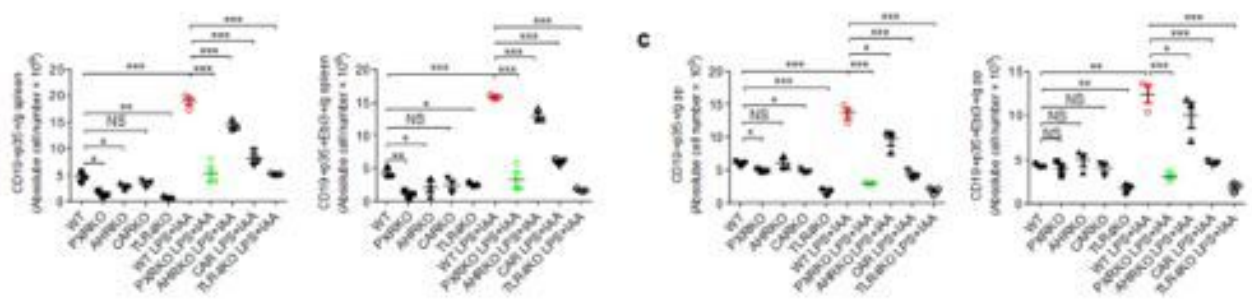

d
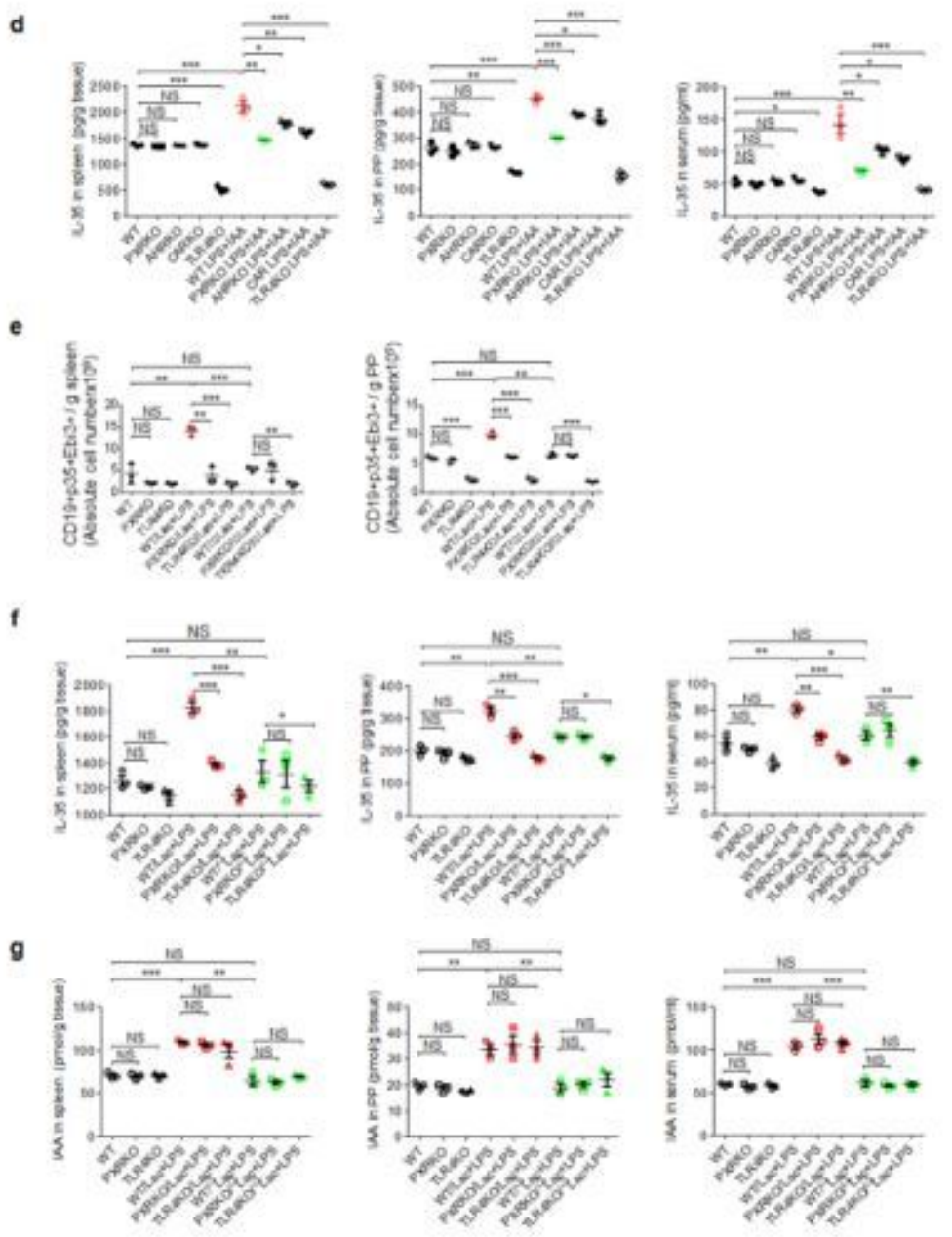

\section{Figure 6}

IAA with LPS mediated IL-35+ B cells need PXR and TLR4. a Percentage of CD19+p35+ or CD19+p35+Ebi3+cells in the spleen cells of WT, PXR KO, TLR4 KO, CAR KO or AhR KO mice with or without exposed to LPS+IAA. b Absolute cell number of CD19+p35+ and CD19+p35+Ebi3+cells in the spleen of WT, PXR KO, TLR4 KO, CAR KO or AhR KO mice with or without injecting LPS+IAA. c Absolute cell number of CD19+p35+ and CD19+p35+Ebi3+ cells in the PP of WT, PXR KO, TLR4 KO, CAR KO or AhR 
KO mice with or without injecting LPS+IAA. d ELISA of IL-35 in the spleen, PP or sera of WT, PXR KO, AhR $\mathrm{KO}, \mathrm{CAR}$ KO or TLR4 KO mice with or without injecting LPS+IAA. e Percentage of CD19+p35+Ebi3+cells in the spleen and PP of WT, PXR KO or TLR4 KO mice with or without infusing lactobacillus or lactobacillus $\triangle$ iaaM . $f$ ELISA of IL-35 in the spleen, PP or sera of WT, PXR KO or TLR4 KO mice with or without infusing lactobacillus or lactobacillus $\triangle$ iaaM. g IAA levels in the spleen, PP or sera of WT, PXR KO or TLR4 KO mice with or without injecting lactobacillus or lactobacillus $\triangle$ iaaM. Student's t-test in all panels, mean \pm SD. ${ }^{*} P<0.05,{ }^{*} \mathrm{P}<0.01$, and ${ }^{\star *} \mathrm{P}<0.001$, NS; No significance.

a

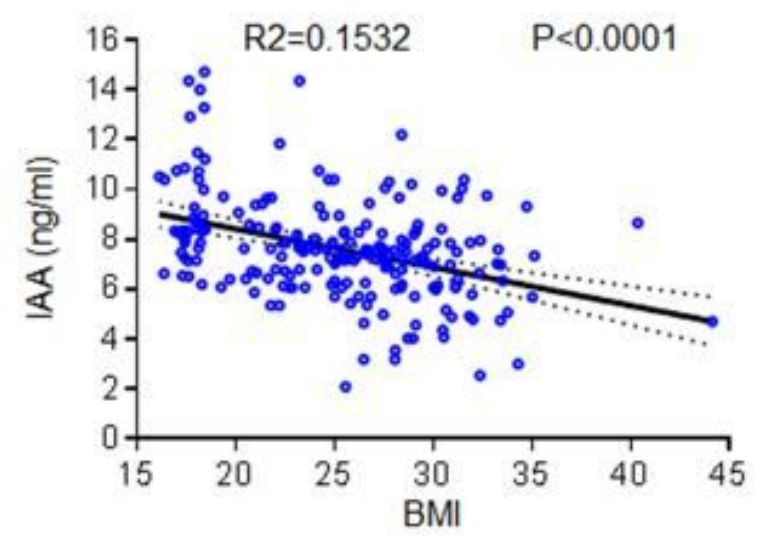

b

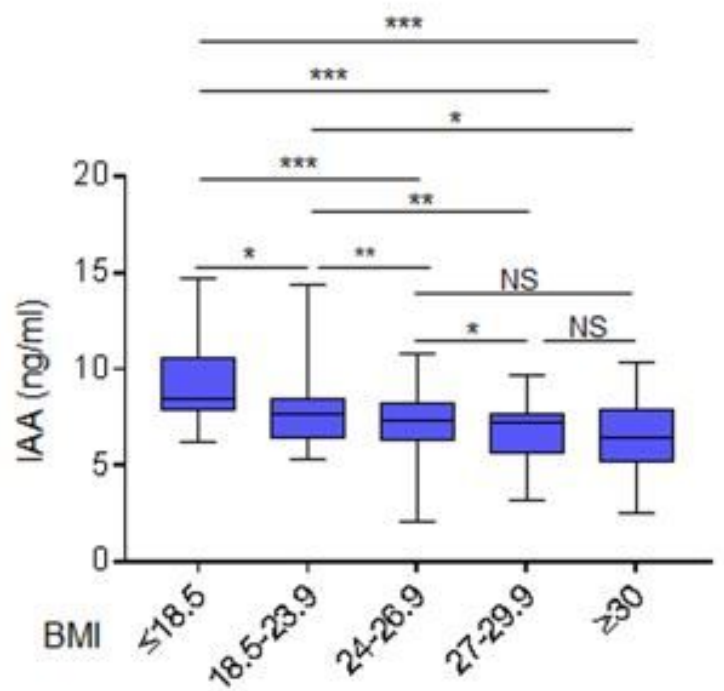

Figure 7

Levels of IAA in the peripheral blood of individuals with obesity. a Negative relationship between BMI and IAA in sera according to analyses of linear regression. $R 2=0.1532$. $b$ IAA levels in peripheral blood of different groups, $B M K$ or $=18.5(n=42), 18.5-23.9(n=41), 24-26.9(n=43), 27-29.9(n=42)$, or $>$ or $=30$ $(n=40)$. Mann-Whitney U test, mean \pm SEM. ${ }^{*} P<0.05, * * P<0.01$, and $* * * P<0.001$; NS, No significance. 